\title{
Spousal Visa Policy and Mixed-Citizenship Couples: Evidence from the End of the Defense Of Marriage Act
}

\author{
Connor Redpath*
}

14 February 2022

\begin{abstract}
I compare mixed-citizenship couple formation under an immigration policy granting spousal visas to one without spousal visas, by leveraging federal same-sex marriage recognition from ending the Defense of Marriage Act. I estimate changes in mixedcitizenship same-sex couple counts and marriage counts, accounting for changes in other same-sex and other mixed-citizenship couples, using a triple difference design. Spousal visa access increases mixed-citizenship coupling by $36 \%$, and mixed-citizenship marriages by $78 \%$. Transfer benefits, health insurance, roommates, moving, or statelevel heterogeneity do not explain the results. Informal calculations suggest 1.5 million people are currently together thanks to spousal visas.
\end{abstract}

JEL Codes: J12, J15, J18, K37

Keywords: Spousal Visa Policy, Same-Sex Couples, Couple Formation, Marriage, Assortative Mating

*I thank Julie Cullen, Tom Vogl, Claire Adida, Eli Berman, Kitt Carpenter, Gordon Dahl, Itzik Fadlon, Carlos Góes, Nathan Hoffmann, Dani Sandler, Ruben Villegas, and participants at the ASSA Annual Meeting 2022 and UC San Diego Applied Lunches for helpful comments and feedback.

Department of Economics, University of California, San Diego, 9500 Gilman Drive - \#508, La Jolla, California, 92093. credpath@ucsd.edu. 
Policy can impact partner choice. One federal marriage policy, spousal visas, grants permanent residency (Green Card) and an expedited path to citizenship for the non-citizen spouse of a citizen. Absent this policy, marrying a citizen violates most non-resident visas and failed visa renewal can dissolve mixed-citizenship couples - where one partner is a citizen and the other is a non-citizen. Therefore, spousal visas reduce barriers to mixed-citizenship couple formation and equip mixed-citizenship couples with a tool to preserve their union in the face of visa uncertainty. This paper studies the effect of access to spousal visas on couple formation, marriage, and assortative mating in the United States.

Measuring how spousal visas affect couple formation, marriage, and assortative mating is challenging because it requires policy variation. Meaningful policy change regarding access to spousal visas has not occurred for decades, when social norms regarding couple formation were substantively different and data sparser. Recently the federal government expanded its definition of spouse and, by extension, expanded access to federal marriage benefits. This followed the Supreme Court decision in United States v. Windsor, which ended the Defense Of Marriage Act (DOMA). This paper exploits this policy change to understand how access to spousal visas affected outcomes.

Passed in 1996, DOMA forbade the federal government from recognising the marriages of same-sex couples. Hence, same-sex couples could not access spousal visas. Non-permanent residents must switch to a spousal visa upon marrying a citizen because marrying a citizen shows an intent to stay in the United States permanently, which violates most nonpermanent visas. Therefore, non-permanent residents were effectively barred from same-sex marriage. However, when DOMA was struck down in 2013, the federal government immediately recognised same-sex marriages and granted married same-sex couples all federal marriage benefits, including spousal visas. Consistent with access to spousal visas increasing net couple formation and marriage rates, the stock of mixed-citizenship same-sex couples recorded in the American Community Survey (ACS) doubled from 2012 to 2017 (Figure 1a), a larger proportional increase than same-citizenship same-sex couples. Similarly, the number of mixed-citizenship same-sex marriages permanently increased tenfold in 2013 (Figure 1b).

This paper analyses the 2008 to 2019 rounds of the ACS, repeated cross-sections that sample $1 \%$ of the United States population each year. The ACS designates a "head-ofhousehold" and lists her or his relationship to every other household member. Possible relationships include "spouse" and "unmarried romantic partner". Therefore, cohabiting same-sex couples are identifiable, but not the sexual orientation of non-coupled individuals or couples that live apart.

To account for unobserved same-sex attracted singles, I use a count model for the analysis. I create state-by-year counts for the number of individuals in four types of couples: mixed- 
citizenship same-sex, same-citizenship same-sex, mixed-citizenship different-sex, and samecitizenship different-sex. The effect of access to spousal visas is the difference between the change over time in number of people in mixed-citizenship same-sex couples and the change over time in the number of people in same-citizenship same-sex couples, minus the difference between the change over time in number of people in mixed-citizenship differentsex couples and the change over time in the number of people in same-citizenship differentsex couples. I use a difference-in-differences-in-differences (DDD) design to identify this effect. I estimate the relative incidence of mixed-citizenship same-sex couples increases $36 \%$, statistically significant at the $1 \%$ level. Similarly, I estimate the relative marriage rate of mixed-citizenship same-sex couples increases 78\%, which jumps up in 2013 and persists. This suggests visa policy absent spousal visas is hostile to mixed-citizenship couples; and spousal visa policy enables mixed-citizenship couples to remain together, increasing net formation, and to marry. This improves the well-being of people (who would be) in mixed-citizenship couples. Lastly, these increases represent an increase in disassortative mating by citizenship by definition. I also find disassortative mating by birth country increases by $11 \%$.

Robustness checks show the results are not driven by: access to other federal benefits, health insurance, roommates relabelling as couples, state-level timing of same-sex marriage legalisation, state-level non-citizen or illegally-present non-citizen shares, or couples moving across state lines. Consistent with new couples forming, the point estimates for younger couples are larger than those for older couples; and mixed-citizenship same-sex couples are relatively more likely to both move within-state.

This is the first paper to directly study spousal visa access. My findings quantify immigration policy's importance for coupling and marriage. In doing so, I contribute new empirical evidence that a large understudied policy affects the rationale for and gains from marriage. This contributes to the literature on the rationale and benefits of coupling and marriage (Becker, 1991; Weiss, 1997; Stevenson and Wolfers, 2007; Edlund, 2013; Lafortune and Low, 2020). This also contributes to the literatures: studying immigrants' marriage patterns (Kelly, 2010; Lafortune, 2013; Adserà and Ferrer, 2015; Kawaguchi and Lee, 2017; Dziadula, 2020); studying immigrant characteristics and visa policies (Jasso, Rosenzweig and Smith, 2000; Guven, Tong and Yuksel, 2020; Wang, 2021); linking government policies to marriage rates (Bitler et al., 2004; Francesconi and Klaauw, 2007; Klerman, 2009; Bobonis, 2011; Abramowitz, 2016); identifying determinants of assortative mating (Abramitzky, Delavande and Vasconcelos, 2011; Mansour and McKinnish, 2014; Chiappori, Salanié and Weiss, 2017); and examining marriage eligibility expansion (Fryer Jr, 2007; Gevrek, 2014; Carpenter et al., 2018; Carpenter, 2020). This paper also contributes to a growing literature on same-sex couples and LBGTQ+ individuals (Black, Sanders and Taylor, 2007; Badgett, 
Carpenter and Sansone, 2021). In particular, it relates to immigrants in same-sex couples (Hoffmann and Velasco, 2021), the assortative mating of same-sex couples (Jepsen and Jepsen, 2002; Ciscato, Galichon and Goussé, 2020), and improved well-being resulting from same-sex marriage (Delhommer and Hamermesh, 2021).

The paper is organised as follows: Section 1 explains the institutional background and policy change. Section 2 describes the data. Section 3 explains the research design and estimation. Section 4 reports and discusses the results. Section 5 concludes.

\section{Background}

\subsection{Marriage and its Benefits}

Marriage is a public commitment made by two partners. Laws regarding dividing assets upon divorce, alimony, child-custody, and medical visitation rights form the legal marriage contract and are state-level laws. States determine marriage eligibility and the strength of the marriage contract.

Marital status matters for government taxes and transfers. "Single/never married" and "Married" are classifications that affect federal and state tax and transfer policy. These policies consider unmarried couples' incomes as separate individuals' incomes, but consider the joint income of married couples. Therefore, couples can marry, divorce, and adjust their labour supply to optimise over tax and transfer benefits. Transfer programs include Medicaid, Supplemental Nutrition Assistance Program, the Earned Income Tax Credit, and any other means tested program. Social Security benefits can also depend on marriage because of surviving spouse benefits. Thus, state and federal governments offer benefits that depend on marital status.

The federal government determines eligibility for immigration and citizenship. Noncitizen spouses of citizens are eligible for: temporary visas while applying for permanent residency; permanent residency visas (Green Cards), conditional upon marriage for two initial years; and United States citizenship after three years of permanent residency, instead of the usual five. These benefits enable mixed-citizenship couples to stay together if other visas aren't granted or renewed, they don't benefit same-citizenship couples. Hence, accessing spousal visas requires mixed-citizenship couple formation, unlike other benefits.

\subsection{Legality of Same-Sex Marriage}

Attitudes towards and legality of same-sex marriage varied during the period of analysis. Some states offered marriage benefits while others banned same-sex marriage, blocking access 
to state-level marriage benefits. In 2004, Massachusetts legalised same-sex marriage for its residents; and California followed suit in 2008, including for non-residents. This spurred a rush in same-sex marriages (visible in Figure 1b). Couples travelled from around the country and world to get married in Californiat In response, Massachusetts began offering same-sex marriage to non-residents in July 2008. With states offering marriage to nonresidents, same-sex couples all over the country could access the marriage contract. Couples residing in states without same-sex marriage would not get state-level benefits but could still access the marriage contract. For example, same-sex couples from Ohio that married in Massachusetts were not married for Ohio tax and transfer purposes. However, upon divorce, couples must divide their marital assets according to Massachusetts law (that is, according to their marriage contracts). In 2015, the Supreme Court ruled in Obergefell v. Hodges that same-sex marriage is legal in all states, requiring the remaining states to immediately legalise, perform, and recognise same-sex marriages ${ }^{2}$

The Defense of Marriage Act (DOMA) banned federal recognition of same-sex marriages in 1996. So as same-sex couples gained access to the marriage contract in 2008 and access to state-level marriage benefits, same-sex couples could not access federal marriage benefits. On June 26, 2013 the Supreme Court ruled in United States v. Windsor, striking down the section of DOMA preventing the federal government from recognising same-sex marriages. That day, the federal government ended a nearly two-decade policy of ignoring same-sex marriages and immediately gave full federal marriage benefits to married same-sex couples.

This paper uses the variation in access to federal marriage benefits for same-sex couples induced by the end of DOMA. This change in federal policy was exogenously ordered after years of litigation and a close decision - made in a branch of government separate from those that grant the benefits or by elected officials. Importantly, this happened after same-sex couples gained access to the marriage contract in 2008.

\subsection{Immigrant and Non-Immigrant Visas}

Immigrant visas (Green Cards) grant holders permanent residence in the United States, whereas non-immigrant visas are issued for "temporary" visits including work and study (United States Customs and Border Protection, 2018). Since non-immigrant visas are for temporary stays, non-immigrant visa holders must not show an intent to stay in the country. For example, if non-immigrant visa holders marry United States permanent residents or citizens, then they show an intent to stay in the United States. Therefore, upon marriage,

\footnotetext{
${ }^{1}$ After Proposition 8 passed in November 2008, same-sex marriage became illegal in California. However, performed marriages remained lawful. California re-legalised same-sex marriage in 2013.

${ }^{2}$ Table 3 provides a timeline for same-sex marriage legalisation.
} 
non-immigrant visas holders must switch to spousal visas to remain in the United States.

Under DOMA, spousal visas were not available to same-sex couples. So non-immigrant visa holders marrying citizens would violate their visa terms with no option to switch to spousal visas. Hence, non-immigrant visa holders were strongly discouraged from marrying same-sex partners prior to 2013, effectively barring them from same-sex marriage. After United States v. Windsor, non-citizens could marry a same-sex partner and expect to obtain immigrant status.

While local authorities provide marriage licenses that grant classification as married for most purposes, proving bona fide marriage for immigration purposes requires an extensive application and interview process. Immigration officers may, for example, check social media, quiz partners' knowledge of each other, and inspect shared living spaces. Indeed, couples benefit from lawyers' assistance during this process (Chetrit, 2011). This process exists to prevent marriage fraud: marriages for the sole purpose of acquiring spousal visas are fraudulent. Marriage fraud risks deportation, jail time, and de-naturalisation (Smith and Elmilady, 2014).

It is unlikely that fraudulent marriages drive the results for three reasons. First, proving bona fide marriage for immigration purposes is challenging. The Immigration Marriage Fraud Amendments in 1986 made proving marriage for immigration purposes so challenging that the number of non-citizen men married to citizen women unambiguously declined (Jasso, Rosenzweig and Smith, 2000). Secondly, it's likely harder for same-sex couples to meet immigration officers' criteria (Carron, 2014). For example: public relationships publicly disclose sexual orientation (which is potentially costly), and filing taxes jointly was not possible in all states. Third, fraudulently married couples need not truly live together,

respond to household surveys as if they are married, or even respond to household surveys at all. However, they should appear to live together to convince immigration officers their marriage is bona fide.

\section{Data}

\subsection{American Community Survey}

I use repeated cross-sections of survey data from the 2008-2019 rounds of the US Census Bureau's American Community Survey (ACS), accessed via IPUMS (Steven Ruggles et al., 2020). Each year, the ACS surveys a new representative sample of $1 \%$ of households, collecting information on marriage, citizenship, transfer benefits, health insurance, and demographics. The ACS is the largest, most detailed data set that identifies same-sex couples 
in the US.

Each household designates one individual as the "head-of-household" (typically the property owner/renter), all other members of the household are then given a "relationship to head". For example: spouse, unmarried romantic partner, parent, child, tenant, roommate, etc. I restrict the sample to heads-of-household and their spouses or unmarried romantic partners.

Couples are "same-sex" if they are both female or both male, and couples are "differentsex" if one is female and the other male. Married couples who do not live together and couples that live together but neither partner is the head-of-household are not identifiable in the sample and are, therefore, excluded from study. Likewise, single individuals' sexual and romantic preferences are unobserved, so they are not in the sample. Lastly, I restrict the sample to individuals aged 18 or older and 64 or younger, regardless of partner's age.

Data on same-sex couples are unreliable prior to 2008 due to coding practices Chesnut, 2008; O'Connell et al. 2010). To address data quality, I do not use earlier surveys and I drop individuals with imputed sex, relationship to head, and citizenship.

Prior to 2013, same-sex married couples were re-coded as unmarried romantic partners and only 2012 has a data quality flag to identify re-coded couples. Therefore, to understand the stock of couples, I pool together married and unmarried couples and order them by survey year. Whereas to understand entry into marriage, I restrict to married couples (from the 2012-2019 surveys only) and order them by marriage year. I keep couples married between 2008 and 2019 to match the years in the main analysis. Note that this selects on marriage duration: couples in the pre-period are married for 0-12 years and couples in the post-period are married for 0-6 years.

\subsection{Summary Statistics}

Table 1 reports weighted individual-level summary statistics for mixed-citizenship same-sex couples (MSS), same-citizenship (not mixed) same-sex couples (NSS), mixed-citizen differentsex couples (MDS), and same-citizenship different-sex couples (NDS), pooled across survey years 2008-2019. The weights make the sample representative of the population, for each survey year. MSS couples are more likely to be married (0.53 compared to 0.33), more likely to be male (0.66 to 0.47$)$, and less likely to have transfer benefits (0.14 to 0.20) than NSS couples. While MSS couples are slightly less likely to have any health insurance than NSS couples (0.91 to 0.95), MSS couples are much more likely than MDS couples to have any health insurance (0.91 to 0.84). These summary statistics do not suggest federal transfer benefits or access to health insurance are likely to explain differential mixed-citizenship or 
same-sex coupling patterns.$^{3}$

\subsection{Couple Counts}

To identify the policy's effect on changes in mixed-citizenship same-sex coupling net of changes in other mixed-citizenship coupling and other same-sex coupling, I employ a triple difference regression design. This design is not defined at the individual level because individuals' preferences over partner sex and partner citizenship are unobserved. Therefore, I aggregate the data from individuals up to state-years.

I create four groups of couples (MSS, NSS, MDS, NDS) and assign each (weighted) individual to one group. Then to create counts, I sum over individuals within group-stateyears. The counts are representative of each group's population within a given state-year.

Figure 1a shows the number of individuals in each couple type on a logarithmic scale, from the 2008 survey until the 2019 survey. Notably, the number of individuals in differentsex relationships remains stable, while the number of individuals in same-sex relationships increases. For MSS couples, the number triples from 2012 to 2017.

Figure $1 \mathrm{~b}$ shows the number of married individuals in each couple type, plotted by their year of marriage, observed in the 2019 survey. While the number of married differentsex couples remains relatively stable, the number of married same-sex couples increases substantially. The number of individuals in NSS marriages and in MSS marriages increases tenfold, virtually overnight in 2013 for MSS marriages. There is also a jump in NSS marriages in 2008, because California legalised same-sex marriage and couples rushed from all over the country to marry.

Lastly, these groups are the intersections of two pairs of disjoint sets of couples: same/different-sex and mixed-/same-citizenship. For ancillary analyses, I also group couples by another couple-level binary variable. For example, an indicator for: receipt of a federal transfer benefit, health insurance type, disassortative mating characteristics, or moving within the past year.

\section{Method}

I employ a difference-in-differences-in-differences (DDD) design and estimate a Conditional Fixed Effects Poisson regression model of Hausman, Hall and Griliches (1984) by QuasiMaximum Likelihood to identify the effect of access to spousal visas on couple formation

\footnotetext{
${ }^{3}$ Tables 4,5 , and 6 provide summary statistics for additional variables and for married couples only.
} 
and assortative mating, as follows:

$$
\begin{aligned}
E\left[y_{g s t} \mid \mathbf{x}_{g s t}\right] & =\exp \left(\beta_{0}+\beta_{1} \text { post }_{t}+\beta_{2} M_{g} \times \text { post }_{t}+\beta_{3} S S_{g} \times \text { post }_{t}\right. \\
& \left.+\beta_{4} M_{g} \times S S_{g} \times \text { post }_{t}+\sigma_{g s}+\tau_{t}+\Gamma_{1} \mathbf{X}_{g s t}+\Gamma_{2} \mathbf{X}_{s t}\right) .
\end{aligned}
$$

Where $y_{g s t}$ is the number of individuals in group $g$, in state $s$, in year $t ; \mathrm{M}_{g}$ is an indicator variable for mixed-citizenship; $\mathrm{SS}_{g}$ is an indicator variable for same-sex; post $_{t}$ is an indicator variable for the post-period, when married same-sex couples can access spousal visas; $\sigma_{g s}$ are group-state fixed effects; $\tau_{t}$ are year fixed effects; $t$ are survey years or marriage years. $\mathbf{X}_{g s t}$ are group-state-year-level covariates: counts for the number of couples with any transfer benefits and any health insurance. $\mathbf{X}_{s t}$ are state-year-level covariates: individual population shares for male, white, Hispanic, black, non-citizen, naturalised, student, active-duty military, welfare

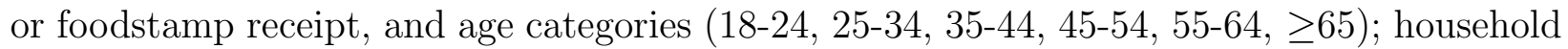
population shares for cohabitation; proportion of different-sex cohabiting couples that are unmarried; and median family income.

$\beta_{4}$ is the coefficient of interest: $\exp \left(\beta_{4}\right)$ is the incidence rate ratio of the increase in MSS coupled individuals relative to the increase in NSS coupled individuals and net of the same ratio for MDS coupled individuals relative to NDS coupled individuals.

The Poisson model has a log-linear relationship between the dependent and independent variables. This has two advantages. First, it can implicitly control for singles' sexual orientation. Suppose the sub-populations with same-sex attraction and different-sex attraction are constant within states, or suppose they evolve annually the same way across states. Take this number or growth rate as given. Then an increase in a group's sub-population is interpretable as an increase in the coupling rate for the sub-population whose preferences align with that group. For example, an increase in mixed-citizenship same-sex couples is also interpretable as an increase in the proportion of same-sex attracted individuals in a mixed-citizenship same-sex couple. Thus $\exp \left(\beta_{4}\right)$ is interpretable as the incidence rate ratio (IRR) of the mixed-citizenship coupling rate relative to the same-citizenship coupling rate for same-sex attracted individuals, net of the ratio of the mixed-citizenship coupling rate relative to the same-citizenship coupling rate for different-sex attracted individuals.

Second, the Poisson model does not drop observations with zero couples, as would the typical log-linear model. (The typical log-linear model has the logarithm on the inside of the expectation.) Hence, despite the scarcity of MSS couples in small states, the Poisson model maintains a balanced panel and representativeness for all states. This avoids restricting the sample to large states or complicating interpretation. Both unbalanced panels and covariates can complicate interpretation (Borusyak, Jaravel and Spiess, 2021). 
The conditional fixed effects Poisson model partials out the fixed effects, so $\sigma_{g s}$ and $\tau_{t}$ are not estimated. Similarly, indicator variables $\mathrm{M}_{g}$ and $\mathrm{SS}_{g}$ are not included in Equation (1) because they are subsumed by $\sigma_{g s}$.

I estimate the model using quasi-maximum likelihood. Therefore, estimates are consistent assuming the mean of the dependent variable is correctly specified (Gourieroux, Monfort and Trognon, 1984). That is, Quasi-Maximum Likelihood Estimation (QMLE) for Poisson regression does not assume the mean and variance are equal| Instead, Quasi-MLE computes the variance/covariance matrix using the outer product of the gradient vector. These QMLE robust standard errors do not assume a Poisson distribution, are robust to arbitrary patterns of serial correlation (Wooldridge, 1999) and are, therefore, not subject to the problems described by Bertrand, Duflo and Mullainathan (2004) regarding difference-in-differences inference. I cluster the standard errors at the group-state-level in all specifications.

For the difference-in-differences-in-differences design to isolate the effect, the groups must have parallel pre-trends. Dynamic estimates also provide insight into how the effects evolve over time. Therefore, I estimate the following:

$$
\begin{aligned}
E\left[y_{g s t} \mid \mathbf{x}_{g s t}\right]=\exp (\alpha & +\sum_{k=2008}^{2019} \delta_{k} M_{g} \times 1\{t=k\}_{t} \\
& +\sum_{k=2008}^{2019} \gamma_{k} S S_{g} \times 1\{t=k\}_{t} \\
& +\sum_{k=2008}^{2019} \beta_{k} M_{g} \times S S_{g} \times 1\{t=k\}_{t} \\
& \left.+\sigma_{g s}+\tau_{t}\right),
\end{aligned}
$$

where $\beta_{2012}, \gamma_{2012}, \delta_{2012}, \tau_{2012}$ are omitted, then test that

$$
\beta_{2008}=\beta_{2009}=\beta_{2010}=\beta_{2011}=0 .
$$

For Poisson regression, the pre-trends test yields a $\chi^{2}$-statistic instead of an $F$-statistic.

I estimate Equation 1 for couples married between 2008 and 2019 and surveyed between 2012 and 2019. As mentioned above, coding practices prevent observing same-sex couples' marriage years before 2012. So this sample selects on marriage duration. Instead of Survey Year, $t$ represents Marriage Year.

Ordering couples by their marriage year (omitting unmarried couples) instead of the

\footnotetext{
${ }^{4}$ The Poisson probability distribution has the property of equal mean and variance and the generic MLE Poisson regression assumes this.
} 
survey year is useful for two reasons. First, the survey year estimates capture changes in the stock of couples. The marriage year estimates capture entry into marriage, hence they represent a flow into marriage and marriage rates. The dynamic estimates from the marriage specification also inform whether the relative flow into mixed-citizen same-sex couples is temporary or persistent, which is important for understanding the policy. Second, marriage year estimates provide a simple robustness check: the response should only come in the post-period. That is, if the policy change facilitates MSS coupling, then those couples who marry should marry after the policy change.

\section{Results \& Discussion}

\subsection{Main Results}

Table 2 reports the Poisson Conditional Fixed Effects quasi-maximum likelihood estimates for the difference-in-differences-in-differences effect of spousal visa access on the number of mixed-citizenship same-sex coupled individuals or married individuals, described in Equation (1). The coefficient of interest is for post $\times$ Same-Sex Couple $\times$ Mixed-Citizenship Couple, given in the first row. The first two columns report the estimates for cohabiting individuals (married and unmarried), where year refers to the year an individual is surveyed. The second two columns report the estimates for cohabiting married individuals, where year refers to the year of marriage. The first and third columns' estimates are from models without covariates, whereas the other two include them. The parallel pre-trends test statistics and p-values, described by Equations (2) and (3), are at the bottom of the table. Finally, Figure 2 plots the dynamic estimates, described by Equation (2).

This paper's primary effect of interest is in Column 1 of Table 2. The increase in mixedcitizenship same-sex coupled individuals is $0.304 \mathrm{log}$ points. The exponentiated coefficient, the relative IRR, is 1.355 with a standard error of 0.076 . This represents a $35.5 \%$ increase in mixed-citizenship same-sex coupling, statistically significant at the $1 \%$ level. The $\chi^{2}$-statistic for parallel pre-trends is 3.174 , which fails to reject the assumption of parallel pre-trends. Pre-period estimates appear stable and post-period estimates trend upwards, in Figure 2a. The steady increase in MSS coupling is consistent with higher net couple formation. Higher net couple formation results from decreased dissolution or increased formation. Hence, this result suggests fewer dissolutions resulting from immigration policy and more formations resulting from greater value to MSS coupling. (MSS matches are relatively more valuable in the post-period because they gain access to marriage and spousal visas.)

Column 3 shows the increase in mixed-citizenship same-sex married individuals is 0.577 
$\log$ points. The relative IRR is 1.780 with a standard error of 0.323 . This represents a $78.0 \%$ increase in mixed-citizenship same-sex marriages, statistically significant at the $5 \%$ level. The $\chi^{2}$ statistic for parallel pre-trends is 1.276 , which fails to reject the assumption of parallel pre-trends. Figure $2 \mathrm{~b}$ plots the dynamic estimates. The 2008 estimate is offtrend because a disproportionate number of same-citizenship same-sex marriages occurred when California legalised same-sex marriage that summer. In 2013, the estimates jump to a permanently higher level. This is consistent with non-permanent residents gaining the right to marry a same-sex partner without visa penalties.

The estimates in Columns 2 and 4 are from a model including covariates. They are smaller but not statistically different. This means other federal transfer benefits, health insurance, or state-year demographic fluctuations do not explain the result.

\subsection{Ancillary Results}

\subsubsection{Alternative Explanations}

The DDD design accounts for aggregate changes in both same-sex couples and mixedcitizenship couples. A credible explanation for the results must, therefore, explain why mixed-citizenship same-sex couples are differentially affected. Spousal visas, for example, matter to mixed-citizenship couples only and same-sex couples recently gained access to them. Other alternatives do not offer credible explanations for differential treatment of

MSS couples. Specifically, I find no evidence to support alternative explanations related to transfer benefits, health insurance, moving across state lines, state-level timing of same-sex marriage legalisation, the non-citizen population, the illegally present non-citizen population, same-sex couples masquerading as roommates, or non-citizen partners' birth countries.

\subsubsection{Mechanism}

Given the results and the institutional setting, I expect non-permanent residents drive the results. Because removing restrictions on their marriages should increase their marriages; and removing pressure to dissolve from visa challenges should increase the stock of couples over time. I cannot test this mechanism directly, because visa or residency status is unobserved. Nevertheless, I find results consistent with this mechanism; and I find results inconsistent with disproportionate increases in "mail order" spouses or marriage fraud. 


\subsubsection{Assortative Mating}

Mixed-citizenship couples are by definition disassortatively matched by citizenship. Furthermore, the increase in MSS couples naturally increases the proportion of same-sex couples with the characteristics of MSS couples.$^{5}$ Thus, increases in mixed-citizenship couples have implications for assortative mating.

\section{Conclusion}

The Defense of Marriage Act was not merely symbolic, instead it tore mixed-citizenship same-sex couples apart. It prevented their marriages and barred access to spousal visas. Mixed-citizenship couples can use spousal visas to maintain legal status when employment or matriculation change, or when facing a visa cap. That's because work or study visas are capped and require employment or matriculation, but spousal visas are unlimited. Simple calculation $\mathbb{6}^{6}$ suggest that DOMA separated 80,000 people from their same-sex partners and prevented 50,000 people from marrying, between 2008 and 2012. Thus DOMA caused some LGB individuals to suffer irrevocable loss.

In a world without spousal visas, mixed-citizenship different-sex couples would also be torn apart. Overall, approximately 1.5 million people have their current partners thanks to spousal visas, as suggested by back-of-the-envelope calculation: 7 . These current matches maximise total utility or social benefit, according to matching theory (Shapley and Shubik, 1971; Choo and Siow, 2006; Dupuy and Galichon, 2014). Hence, without spousal visas, immigration policy reallocates millions of people to new partners or to no partner. In doing so, it lowers the total social benefit of coupling.

\footnotetext{
${ }^{5}$ For example, mixed-citizenship couples are more likely composed of partners: of different races, with large age or education gaps, or born in different countries (Table 4 ).

${ }^{6}$ An estimated 65825 people marry a mixed-citizenship same-sex partner from 2008 to 2012 , based on the 2012-2019 ACSs. After DOMA, there are 1.78 times more marriages. So $65825 \times 0.78=51343$ people are prevented from marrying. Similarly, there are 233489 mixed-citizenship same-sex coupled individuals sampled from 2008 to 2012 in the ACS. After DOMA, there are 1.36 times more couples. So $233489 \times 0.36=$ 84056 people were prevented from forming a couple.

${ }^{7}$ Take the estimate in Table 2 as the true population effect. Then the proportion of mixed-citizenship couples benefiting from a spousal visa is $0.36 / 1.36=0.26$. There are 5729983 mixed-citizenship coupled individuals estimated from the 2019 ACS. So $5729983 \times 0.26=1489796$ people benefit from a spousal visa.
} 


\section{References}

Abramitzky, Ran, Adeline Delavande, and Luis Vasconcelos. 2011. "Marrying Up: The Role of Sex Ratio in Assortative Matching." American Economic Journal: Applied Economics, 3(3): 124-157.

Abramowitz, Joelle. 2016. "Saying, "I Don't": The Effect of the Affordable Care Act Young Adult Provision on Marriage." Journal of Human Resources, 51(4): 933-960.

Adserà, Alícia, and Ana Ferrer. 2015. "Immigrants and Demography: Marriage, Divorce, and Fertility." In Handbook of the Economics of International Migration. Vol. 1 of Handbook of the Economics of International Migration, , ed. Barry R. Chiswick and Paul W. Miller, 315-374. North-Holland.

Badgett, M. V. Lee, Christopher S. Carpenter, and Dario Sansone. 2021. "LGBTQ Economics." Journal of Economic Perspectives, 35(2): 141-170.

Becker, Gary S. 1991. A Treatise on the Family. Harvard University Press.

Bertrand, Marianne, Esther Duflo, and Sendhil Mullainathan. 2004. "How Much Should We Trust Differences-In-Differences Estimates?" The Quarterly Journal of Economics, 119(1): 249-275.

Bitler, Marianne P., Jonah B. Gelbach, Hilary W. Hoynes, and Madeline Zavodny. 2004. "The impact of welfare reform on marriage and divorce." Demography, 41(2): 213-236.

Black, Dan A., Seth G. Sanders, and Lowell J. Taylor. 2007. "The Economics of Lesbian and Gay Families." Journal of Economic Perspectives, 21(2): 53-70.

Bobonis, Gustavo J. 2011. "The Impact of Conditional Cash Transfers on Marriage and Divorce." Economic Development and Cultural Change, 59(2): 281-312. Publisher: The University of Chicago Press.

Borusyak, Kirill, Xavier Jaravel, and Jann Spiess. 2021. "Revisiting Event Study Designs: Robust and Efficient Estimation." arXiv:2108.12419 [econ].

Carpenter, Christopher, and Gary J. Gates. 2008. "Gay and lesbian partnership: Evidence from California." Demography, 45(3): 573-590.

Carpenter, Christopher S. 2020. "The Direct Effects of Legal Same-Sex Marriage in the United States: Evidence From Massachusetts." Demography, 57(5): 1787-1808. 
Carpenter, Christopher, Samuel T Eppink, Gilbert Gonzales Jr, and Tara McKay. 2018. "Effects of Access to Legal Same-Sex Marriage on Marriage and Health: Evidence from BRFSS." National Bureau of Economic Research Working Paper 24651.

Carron, Anna. 2014. "Marriage-Based Immigration for Same-Sex Couples after DOMA: Lingering Problems of Proof and Predjudice Notes and Comments." Northwestern University Law Review, 109(4): 1021-1052.

Chesnut, John. 2008. "Effects of Using a Grid versus a Sequential Form on the ACS Basic Demographic Data." US Census Bureau Decennial Statistical Studies Division.

Chetrit, Samantha L. 2011. "Surviving an Immigration Marriage Fraud Investigation: All You Need is Love, Luck, and Tight Privacy Controls Note." Brooklyn Law Review, 77(2): 709-744.

Chiappori, Pierre-André, Bernard Salanié, and Yoram Weiss. 2017. "Partner Choice, Investment in Children, and the Marital College Premium." American Economic Review, 107(8): 2109-2167.

Choo, Eugene, and Aloysius Siow. 2006. "Who Marries Whom and Why." Journal of Political Economy, 114(1): 175-201.

Ciscato, Edoardo, Alfred Galichon, and Marion Goussé. 2020. "Like Attract Like? A Structural Comparison of Homogamy across Same-Sex and Different-Sex Households." Journal of Political Economy, 128(2): 740-781.

Delhommer, Scott M., and Daniel S. Hamermesh. 2021. "Same-Sex Couples and the Gains to Marriage: The Importance of the Legal Environment." Journal of Policy Analysis and Management, 40(4): 1120-1139.

Dillender, Marcus. 2014. "The Death of Marriage? The Effects of New Forms of Legal Recognition on Marriage Rates in the United States." Demography, 51(2): 563-585.

Dupuy, Arnaud, and Alfred Galichon. 2014. "Personality Traits and the Marriage Market." Journal of Political Economy, 122(6): 1271-1319.

Dziadula, Eva. 2020. "Marriage and Citizenship Among U.S. Immigrants: Who Marries Whom and Who Becomes a Citizen?" Eastern Economic Journal, 46(1): 34-52.

Edlund, Lena. 2013. "The Role of Paternity Presumption and Custodial Rights for Understanding Marriage Patterns." Economica, 80(320): 650-669. 
Francesconi, Marco, and Wilbert van der Klaauw. 2007. "The Socioeconomic Consequences of "In-Work" Benefit Reform for British Lone Mothers." Journal of Human Resources, XLII(1): 1-31.

Fryer Jr, Roland G. 2007. "Guess Who's Been Coming to Dinner? Trends in Interracial Marriage over the 20th Century." Journal of Economic Perspectives, 21(2): 71-90.

Gevrek, Deniz. 2014. "Interracial Marriage, Migration and Loving." The Review of Black Political Economy, 41(1): 25-60.

Gourieroux, C., A. Monfort, and A. Trognon. 1984. "Pseudo Maximum Likelihood Methods: Applications to Poisson Models." Econometrica, 52(3): 701-720.

Guven, Cahit, Lan Anh Tong, and Mutlu Yuksel. 2020. "Australia's Immigration Selection System and Labour Market Outcomes in a Family Context: Evidence from Administrative Data." Economic Record, 96(S1): 50-77.

Hansen, Mary Eschelbach, Michael E. Martell, and Leanne Roncolato. 2020. "A labor of love: The impact of same-sex marriage on labor supply." Review of Economics of the Household, 18(2): 265-283.

Hausman, Jerry, Bronwyn H. Hall, and Zvi Griliches. 1984. "Econometric Models for Count Data with an Application to the Patents-R \& D Relationship." Econometrica, 52(4): 909-938.

Hoffmann, Nathan I, and Kristopher Velasco. 2021. "Making Migration Sexy: How LGB Policies Influence International Migration." Working Paper.

Jasso, Guillermina, Mark R. Rosenzweig, and James P. Smith. 2000. "The Changing Skill of New Immigrants to the United States: Recent Trends and Their Determinants." In Issues in the Economics of Immigration. 185-226. University of Chicago Press.

Jepsen, Lisa K., and Christopher A. Jepsen. 2002. "An Empirical Analysis of the Matching Patterns of Same-Sex and Opposite-Sex Couples." Demography, 39(3): 435-453.

Kawaguchi, Daiji, and Soohyung Lee. 2017. "Brides for Sale: Cross-Border Marriages and Female Immigration." Economic Inquiry, 55(2): 633-654.

Kelly, Claudia Smith. 2010. "The Influence of a Change in Immigration Law on US Marriage Rates." Eastern Economic Journal, 36(4): 500-522. 
Klerman, Jacob Alex. 2009. "Family Structure." In Welfare Reform Effects of a Decade of Change. 173-198. Harvard University Press.

Lafortune, Jeanne. 2013. "Making Yourself Attractive: Pre-marital Investments and the Returns to Education in the Marriage Market." American Economic Journal: Applied Economics, 5(2): 151-178.

Lafortune, Jeanne, and Corinne Low. 2020. "Collateralized Marriage." National Bureau of Economic Research Working Paper 27210.

Mansour, Hani, and Terra McKinnish. 2014. "Who Marries Differently Aged Spouses? Ability, Education, Occupation, Earnings, and Appearance." The Review of Economics and Statistics, 96(3): 577-580.

National Center for Lesbian Rights. 2018. "Marriage, Domestic Partnerships, and Civil Unions: An overview of relationship recognition for same-sex couples Within the United States." National Center for Lesbian Rights.

O'Connell, Martin, Daphne Lofquist, Tavia Simmons, and Terry Lugaila. 2010. "New Estimates of Same-Sex Couple Households from the American Community Survey." Dallas, Texas.

Shapley, L. S., and M. Shubik. 1971. "The assignment game I: The core." International Journal of Game Theory, 1(1): 111-130.

Smith, Kebharu H., and Suzanne Elmilady. 2014. "Prosecuting Marriage Fraud Conspiracies - Lifting the Veil of Sham Marriage Border Issues." United States Attorneys' Bulletin, 62(6): 44-48.

Steven Ruggles, Sarah Flood, Ronald Goeken, Josiah Grover, Erin Meyer, Jose Pacas, and Matthew Sobek. 2020. "IPUMS USA: Version 10.0 [dataset]." Vol. 2020. Minneapolis, MN:IPUMS.

Stevenson, Betsey, and Justin Wolfers. 2007. "Marriage and Divorce: Changes and their Driving Forces." Journal of Economic Perspectives, 21(2): 27-52.

United States Customs and Border Protection. 2018. "Requirements for Immigrant and Nonimmigrant Visas."

Van Hook, Jennifer, James D. Bachmeier, Donna L. Coffman, and Ofer Harel. 2014. "Can We Spin Straw Into Gold? An Evaluation of Immigrant Legal Status Imputation Approaches." Demography, 52(1): 329-354. 
Wang, Xuening. 2021. "US Permanent Residency, Job Mobility, and Earnings." Journal of Labor Economics, 39(3): 639-671. Publisher: The University of Chicago Press.

Weiss, Yoram. 1997. "The formation and dissolution of families: Why marry? Who marries whom? And what happens upon divorce." In Handbook of Population and Family Economics. Vol. 1A, 81-123. Elsevier.

Wooldridge, Jeffrey M. 1999. "Quasi-Likelihood Methods for Count Data." In Handbook of Applied Econometrics Volume 2: Microeconomics., ed. M. Hashem Pesaran and Peter Schmidt, 321-368. John Wiley \& Sons, Ltd. 
Table 1: Individual-Level Summary Statistics

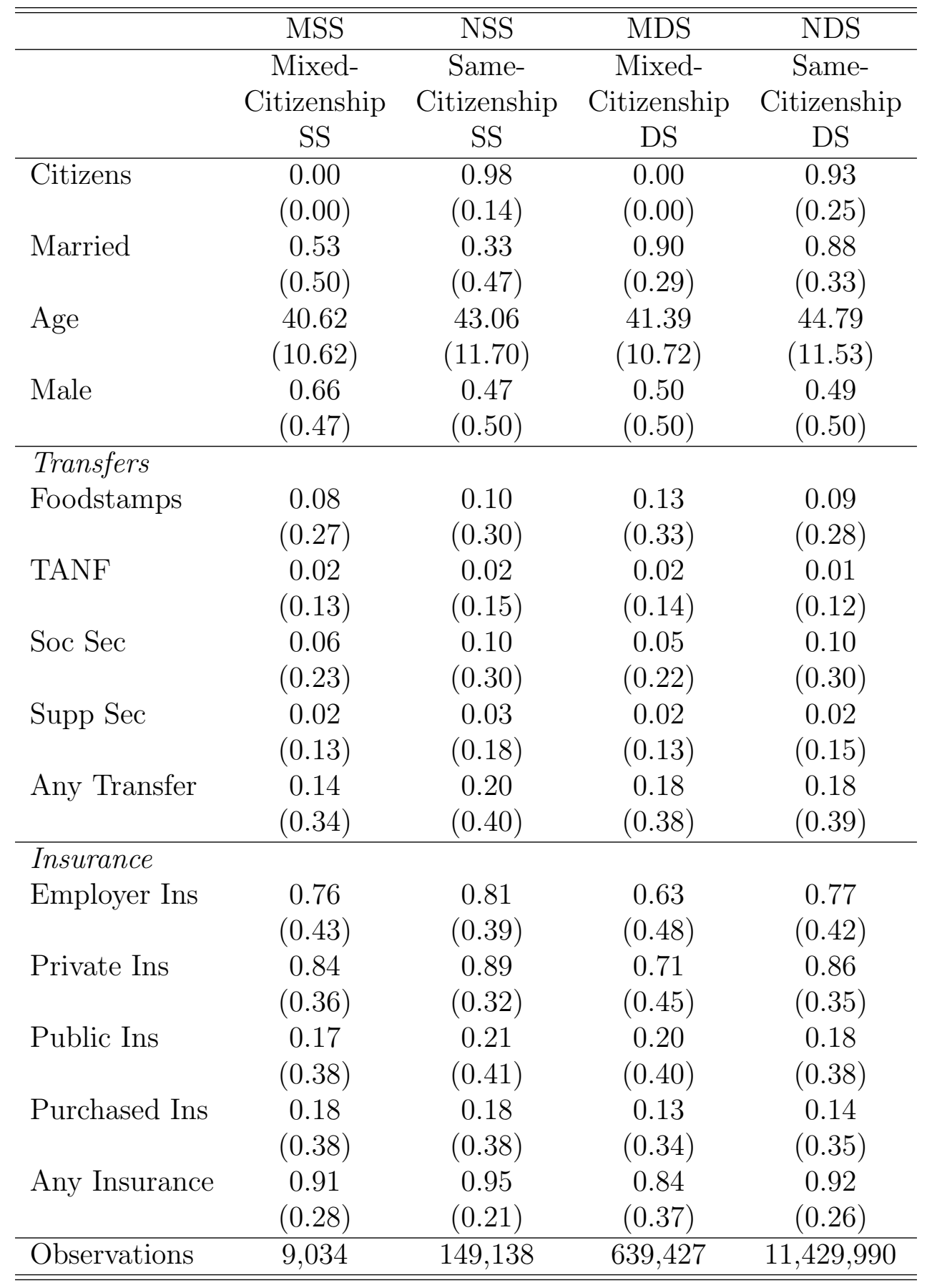

This table reports means and standard deviations for demographic, transfer, and insurance variables. Each column represents individuals in a specific couple type: mixed-citizenship same-sex, same-citizenship samesex, mixed-citizenship different-sex, and same-citizenship different-sex. Data are from the 2008-2019 rounds of American Community Survey. 


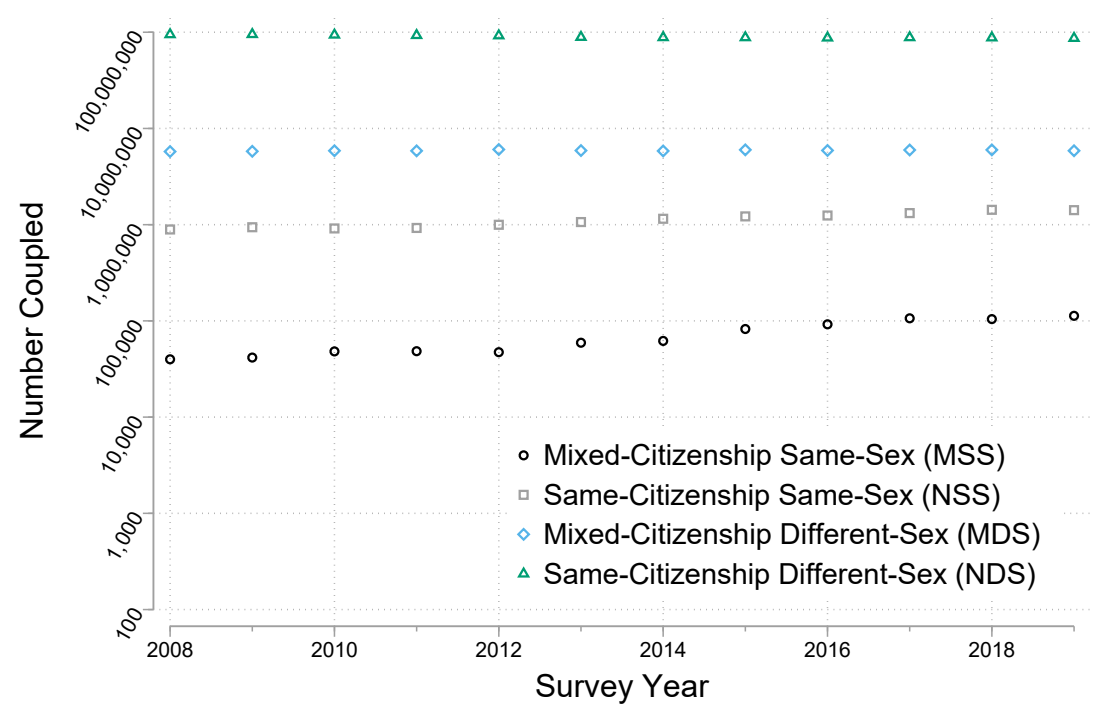

(a) by Survey Year

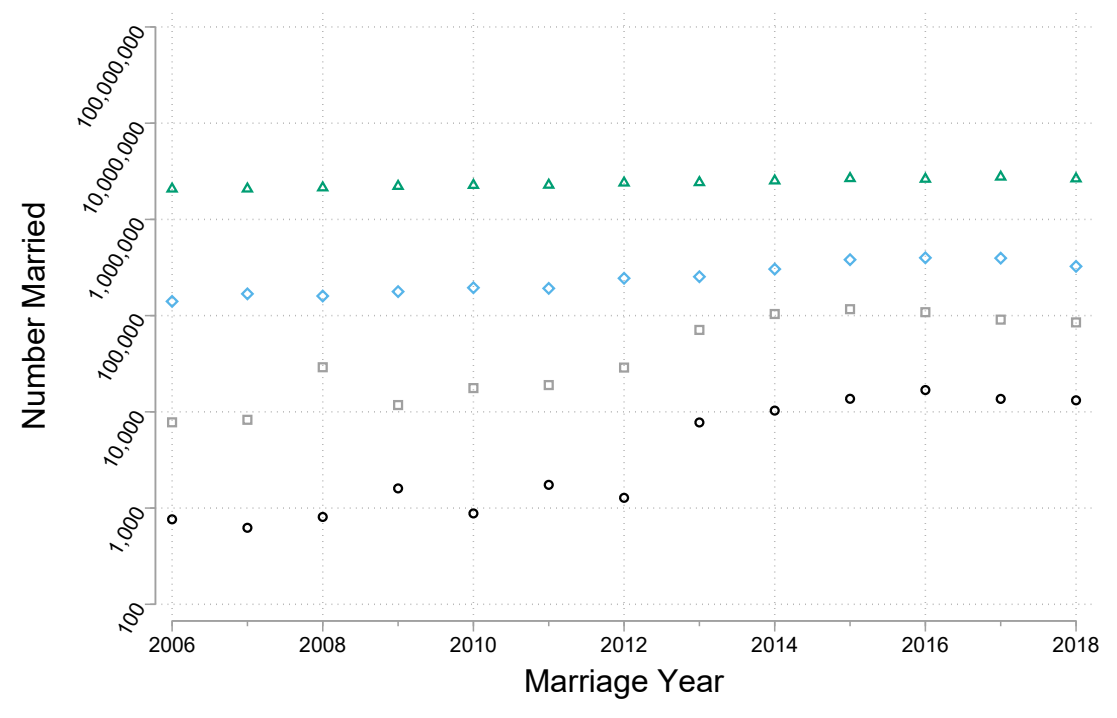

(b) by Marriage Year

\section{Figure 1: Number of Individuals by Couple Type}

Each point is the population estimate for the number of individuals in a given couple type and year. The vertical axes depict the number of individuals on a logarithmic scale. The horizontal axes depict years. The four couple types are determined by the intersection of same- or different-sex and same- or mixed-citizenship. For survey years, each point is a population estimate, representing the United States population in a given survey year. For marriage years, each point represents the population married in a given year conditional on the marriages surviving until 2019; and is representative of the 2019 population. Data are from the 2008 to 2019 rounds of the American Community Survey. Figure 1a uses all years; Figure 1b uses 2019 only. 


\section{Table 2: DDD Estimates For Coupled and Married Individuals}

\begin{tabular}{lcccc}
\hline \hline & \multicolumn{2}{c}{$\begin{array}{c}\text { Coupled Individuals } \\
\text { by Survey Year }\end{array}$} & \multicolumn{2}{c}{ Married Individuals } \\
& by Marriage Year \\
\hline post $\times \mathrm{M} \times \mathrm{SS}$ & 0.304 & 0.278 & 0.577 & 0.466 \\
& $(0.053)$ & $(0.052)$ & $(0.182)$ & $(0.196)$ \\
post $\times \mathrm{SS}$ & 0.367 & 0.357 & 1.398 & 1.317 \\
& $(0.018)$ & $(0.016)$ & $(0.153)$ & $(0.164)$ \\
post $\times \mathrm{M}$ & 0.074 & 0.059 & 0.144 & 0.067 \\
& $(0.015)$ & $(0.013)$ & $(0.016)$ & $(0.035)$ \\
post & -0.062 & -0.020 & -0.745 & 0.173 \\
& $(0.006)$ & $(0.004)$ & $(0.006)$ & $(0.026)$ \\
\hline Observations & 2448 & 2300 & 2405 & 2134 \\
Log Likelihood & $-666,781$ & $-427,173$ & $-14,917,134$ & $-2,841,546$ \\
Covariates & & $\mathrm{X}$ & & $\mathrm{X}$ \\
Relative IRR & 1.355 & 1.321 & 1.780 & 1.593 \\
SE & 0.072 & 0.068 & 0.323 & 0.312 \\
$\mathrm{p}$-value & 0.000 & 0.000 & 0.016 & 0.057 \\
& & & & \\
$\chi^{2}$ Pre-trend Test & 3.174 & 3.902 & 1.276 & 2.109 \\
$\mathrm{p}$-value & 0.529 & 0.419 & 0.865 & 0.716 \\
\hline \hline
\end{tabular}

This table reports the Poisson Conditional Fixed Effects estimates for Equation (1). SS refers to same-sex coupled individuals and M refers to mixed-citizenship coupled individuals. The coefficient of interest is post $\times \mathrm{SS} \times \mathrm{M}$ and the Relative Incidence Rate Ratio $(\mathrm{IRR})$ is the exponentiated coefficient of interest. The $\chi^{2}$ pre-trend test reports the test statistic for the test of parallel pre-trends, described by Equation (3). Standard errors in parentheses, clustered at the group-state level. Data are from the American Community Survey. The first two columns use the 2008-2019 rounds; the second two columns use the 2012-2019 rounds. 


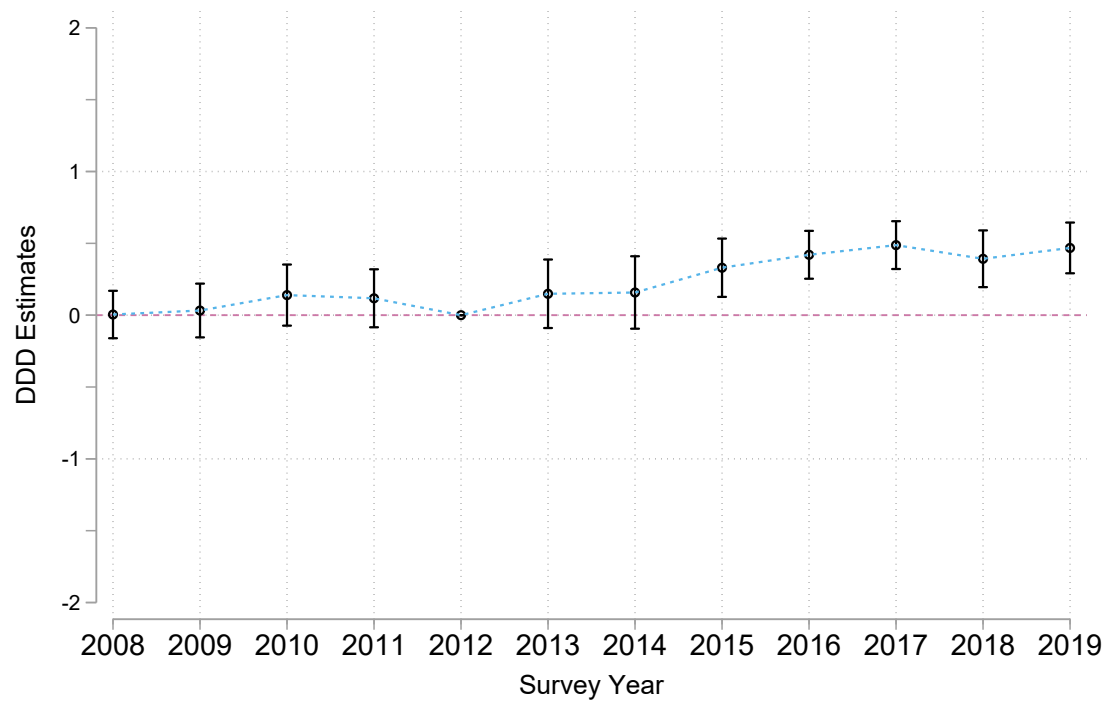

(a) Coupled Individuals by Survey Year

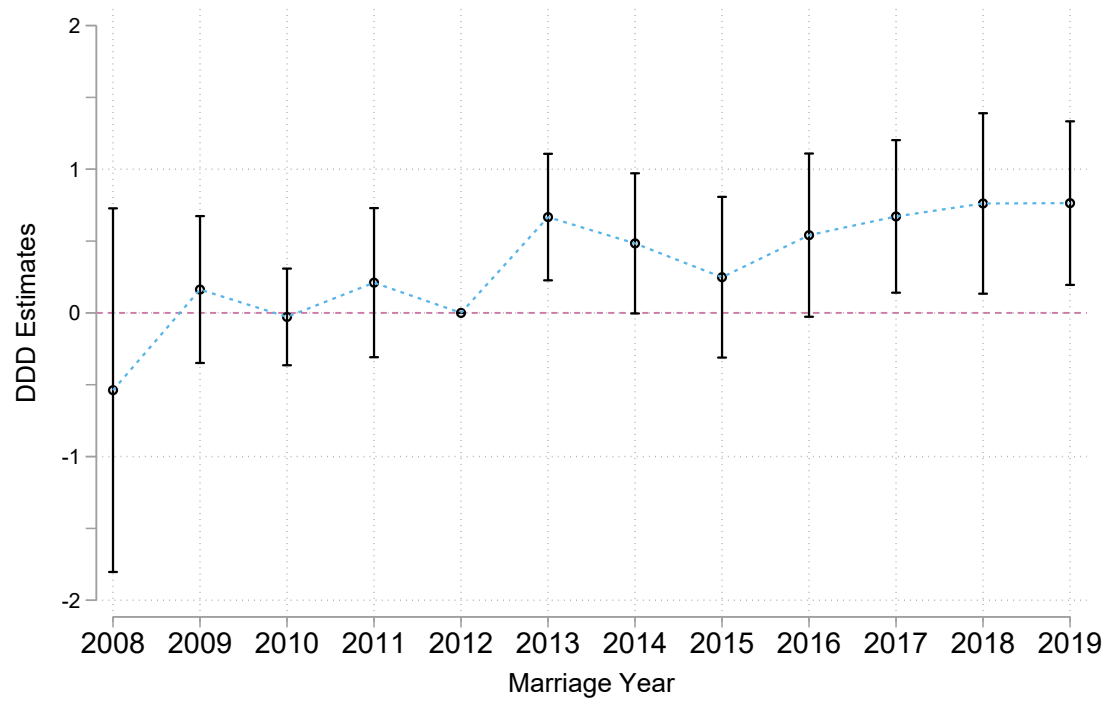

(b) Married Individuals by Marriage Year Figure 2: Dynamic DDD Estimates

This figure plots the Poisson Conditional Fixed Effects estimates for Equation (2), where time is either Survey Year or Marriage Year. Standard errors are clustered at the group-state level. Data are from the American Community Survey. The first subfigure uses the 2008-2019 rounds; the second subfigure uses the 2012-2019 rounds. 


\section{A Online Appendix}

\section{A.1 Timing of State-Level Same-Sex Marriage Laws}

Table 3 lists states by their timing of same-sex marriage legalisation, noting the method and existing alternatives to marriage.

Table 3: Timing of Same-Sex Marriage Legalisation

\begin{tabular}{llll}
\hline \hline State & Effective & Granting Body & Alternatives \\
\hline Massachusetts & May 17, 2004 & State Court & \\
Connecticut & Nov 12, 2008 & State Court & Civil Unions, 2005 \\
Iowa & May 25, 2009 & State Court & \\
Vermont & Sep 1, 2009 & Legislature & Civil Unions, 2000 \\
New Hampshire & Jan 1, 2010 & Legislature & Civil Unions, 2008 \\
Dist of Col & Mar 3, 2010 & Legislature & Domestic Partnership, 2002 \\
& & & Recognition of Marriages, 2009 \\
New York & Jul 24, 2011 & Legislature & Recognition of Marriages, 2010 \\
Washington & Dec 9,2012 & Voters \& Leg & Domestic Partnerships, 2007 \\
Maine & Dec 29,2012 & Voters & Domestic Partnerships, 2004 \\
Maryland & Jan 1, 2013 & Voters \& Leg & Domestic Partnerships, 2008 \\
California & Jun 28,2013 & Federal Court & Domestic Partnerships, 2000/2005 \\
& & State Court & Legal from June 16-Nov 4, 2008 \\
Delaware & Jul 1, 2013 & Legislature & Civil Unions, 2012 \\
Minnesota & Aug 1, 2013 & Legislature & \\
Rhode Island & Aug 1, 2013 & Legislature & Civil Unions, 2011 \\
New Jersey & Oct 21, 2013 & State Court & Civil Unions, 2007 \\
Hawai'i & Dec 2, 2013 & Legislature & Civil Unions, 2012 \\
& & & Reciprocal Beneficiaries, 1997 \\
New Mexico & Dec 19,2013 & State Court & \\
Oregon & May 19,2014 & Federal Court & Domestic Partnerships, 2008 \\
Pennsylvania & May 20,2014 & Federal Court & \\
Illinois & Jun 1, 2014 & Legislature & Civil Unions, 2011 \\
& & &
\end{tabular}




\begin{tabular}{|c|c|c|c|}
\hline \multirow{3}{*}{$\begin{array}{l}\text { Oklahoma } \\
\text { Utah }\end{array}$} & Oct 6,2014 & Federal Court & \multirow[b]{3}{*}{ Legal from Dec 20, 2013-Jan 6, 2014} \\
\hline & Oct 6,2014 & Federal Court & \\
\hline & & Federal Court & \\
\hline Virginia & Oct 6,2014 & Federal Court & \\
\hline Colorado & Oct 7, 2014 & Federal Court & $\begin{array}{l}\text { Designated Beneficiary, } 2009 \\
\text { Civil Unions, } 2013\end{array}$ \\
\hline Indiana & Oct 7, 2014 & Federal Court & \\
\hline Wisconsin & Oct 7, 2014 & Federal Court & Domestic Partnerships, 2009 \\
\hline Nevada & Oct 9,2014 & Federal Court & Domestic Partnerships, 2009 \\
\hline West Virginia & Oct 9, 2014 & Federal Court & \\
\hline North Carolina & Oct 10,2014 & Federal Court & \\
\hline Idaho & Oct 15,2014 & Federal Court & \\
\hline Alaska & Oct 17, 2014 & Federal Court & \\
\hline Arizona & Oct 17,2014 & Federal Court & \\
\hline Wyoming & Oct 21, 2014 & Federal Court & \\
\hline Montana & Nov 19, 2014 & Federal Court & \\
\hline South Carolina & Nov 19, 2014 & Federal Court & \\
\hline Florida & Jan 6, 2015 & Federal Court & \\
\hline \multirow[t]{2}{*}{ Alabama } & Jun 26,2015 & Federal Court & \\
\hline & & Federal Court & Legal from Feb 9-March 3, 2015 \\
\hline \multirow[t]{2}{*}{ Arkansas } & Jun 26, 2015 & Federal Court & \\
\hline & & State Court & Legal from May 9-16, 2014 \\
\hline Georgia & Jun 26, 2015 & Federal Court & \\
\hline \multirow[t]{2}{*}{ Kansas } & Jun 26,2015 & Federal Court & \\
\hline & & County Courts & Up to counties since Nov 13,2014 \\
\hline Kentucky & Jun 26, 2015 & Federal Court & \\
\hline Louisiana & Jun 26,2015 & Federal Court & \\
\hline \multirow[t]{2}{*}{ Michigan } & Jun 26,2015 & Federal Court & \\
\hline & & Federal Court & Briefly legal on March 21, 2014 \\
\hline Mississippi & Jun 26,2015 & Federal Court & \\
\hline \multirow[t]{3}{*}{ Missouri } & Jun 26, 2015 & Federal Court & Recognition of Marriages Oct 3, 2014 \\
\hline & & Federal Court & Legal since Nov 5, 2014 in St Louis \\
\hline & & Federal Court & Since Nov 7, 2014 in Jackson County \\
\hline Nebraska & Jun 26, 2015 & Federal Court & \\
\hline North Dakota & Jun 26,2015 & Federal Court & \\
\hline Ohio & Jun 26, 2015 & Federal Court & \\
\hline South Dakota & Jun 26, 2015 & Federal Court & \\
\hline Tennessee & Jun 26, 2015 & Federal Court & \\
\hline Texas & Jun 26,2015 & Federal Court & \\
\hline
\end{tabular}

"Effective" refers to the effective date when same-sex marriage became permanently legal. Some indigenous tribes allow same-sex marriage before or after it is legalised elsewhere in the state. Massachusetts allows out-of-state same-sex couples to marry since July 31, 2008. Exceptions to the marriage laws are only listed for states forced to legalise same-sex marriage resulting from the Supreme Court ruling in Obergefell $v$. Hodges. Created using Table 1 from Hansen, Martell and Roncolato (2020), with additional information from the National Center for Lesbian Rights (2018). 


\section{A.2 Ancillary Summary Statistics}

\section{Table 4: Additional Individual-Level Summary Statistics - All Co- habiting Couples}

\begin{tabular}{|c|c|c|c|c|}
\hline & MSS & NSS & MDS & NDS \\
\hline & Mixed- & Same- & Mixed- & Same- \\
\hline & Citizenship & Citizenship & Citizenship & Citizenship \\
\hline & SS & SS & DS & DS \\
\hline \multirow[t]{2}{*}{ Survey Year } & $2,014.74$ & $2,014.08$ & $2,013.53$ & $2,013.40$ \\
\hline & $(3.32)$ & $(3.44)$ & $(3.44)$ & $(3.46)$ \\
\hline \multirow[t]{2}{*}{ year married } & $1,252.72$ & 947.75 & $1,880.05$ & $1,836.24$ \\
\hline & $(973.52)$ & $(1,000.40)$ & $(477.38)$ & $(540.90)$ \\
\hline \multirow{2}{*}{$\begin{array}{l}1 \text { Born Abroad } \\
\text { Other Domestic }\end{array}$} & 0.74 & 0.08 & 0.52 & 0.06 \\
\hline & $(0.44)$ & $(0.27)$ & $(0.50)$ & $(0.24)$ \\
\hline \multirow[t]{2}{*}{ Interracial Couple } & 0.41 & 0.21 & 0.20 & 0.10 \\
\hline & $(0.49)$ & $(0.41)$ & $(0.40)$ & $(0.30)$ \\
\hline \multirow{2}{*}{$\begin{array}{l}1 \text { In School } \\
\text { Other Out }\end{array}$} & 0.16 & 0.12 & 0.10 & 0.08 \\
\hline & $(0.37)$ & $(0.33)$ & $(0.30)$ & $(0.27)$ \\
\hline \multirow[t]{2}{*}{ Educ Gap $\geq 3$ Years } & 0.32 & 0.22 & 0.32 & 0.20 \\
\hline & $(0.47)$ & $(0.42)$ & $(0.47)$ & $(0.40)$ \\
\hline \multirow[t]{2}{*}{ Age Gap $\geq 5$ Years } & 0.57 & 0.46 & 0.43 & 0.29 \\
\hline & $(0.50)$ & $(0.50)$ & $(0.50)$ & $(0.45)$ \\
\hline \multirow[t]{2}{*}{ Both Speak English Very Well } & 0.97 & 1.00 & 0.92 & 0.98 \\
\hline & $(0.18)$ & $(0.06)$ & $(0.27)$ & $(0.13)$ \\
\hline \multirow[t]{2}{*}{ Both University Educated } & 0.33 & 0.33 & 0.18 & 0.24 \\
\hline & $(0.47)$ & $(0.47)$ & $(0.38)$ & $(0.43)$ \\
\hline \multirow[t]{2}{*}{ Couple Moved between Country } & 0.00 & 0.00 & 0.01 & 0.00 \\
\hline & $(0.06)$ & $(0.04)$ & $(0.07)$ & $(0.05)$ \\
\hline \multirow[t]{2}{*}{ Couple Moved between States } & 0.02 & 0.02 & 0.02 & 0.02 \\
\hline & $(0.15)$ & $(0.15)$ & $(0.13)$ & $(0.13)$ \\
\hline \multirow[t]{2}{*}{ Couple Moved within State } & 0.12 & 0.12 & 0.11 & 0.09 \\
\hline & $(0.33)$ & $(0.33)$ & $(0.31)$ & $(0.28)$ \\
\hline \multirow[t]{2}{*}{ Couple Moved to a new State } & 0.03 & 0.03 & 0.02 & 0.02 \\
\hline & $(0.16)$ & $(0.16)$ & $(0.15)$ & $(0.14)$ \\
\hline \multirow[t]{2}{*}{1 Partner Abroad Last Year } & 0.01 & 0.00 & 0.02 & 0.00 \\
\hline & $(0.11)$ & $(0.06)$ & $(0.13)$ & $(0.05)$ \\
\hline \multirow[t]{2}{*}{ HH Income $>$ State Median } & 0.71 & 0.75 & 0.55 & 0.73 \\
\hline & $(0.45)$ & $(0.44)$ & $(0.50)$ & $(0.45)$ \\
\hline \multirow[t]{2}{*}{ Couple Owns Home } & 0.54 & 0.66 & 0.57 & 0.74 \\
\hline & $(0.50)$ & $(0.48)$ & $(0.50)$ & $(0.44)$ \\
\hline \multirow[t]{2}{*}{ Couple Has Kids } & 0.22 & 0.23 & 0.70 & 0.60 \\
\hline & $(0.41)$ & $(0.42)$ & $(0.46)$ & $(0.49)$ \\
\hline \multirow[t]{2}{*}{ HH Has $\geq 3$ Adults } & 0.18 & 0.13 & 0.16 & 0.10 \\
\hline & $(0.39)$ & $(0.34)$ & $(0.37)$ & $(0.30)$ \\
\hline \multirow[t]{2}{*}{ HH Has $\geq 5$ Bedrooms } & 0.16 & 0.20 & 0.23 & 0.32 \\
\hline & $(0.36)$ & $(0.40)$ & $(0.42)$ & $(0.47)$ \\
\hline Observations & 9034 & 149138 & 639427 & 11429990 \\
\hline
\end{tabular}

This table reports means and standard deviations for additional demographic variables. Each column represents individuals in a specific couple type: mixed-citizenship same-sex, same-citizenship same-sex, mixedcitizenship different-sex, and same-citizenship different-sex. Data are from the 2008-2019 rounds of American Community Survey. 
Table 5: Individual-Level Summary Statistics - Married Individuals

\begin{tabular}{|c|c|c|c|c|}
\hline & MSS & NSS & MDS & NDS \\
\hline & Mixed- & Same- & Mixed- & Same- \\
\hline & Citizenship & Citizenship & Citizenship & Citizenship \\
\hline & SS & SS & DS & DS \\
\hline \multirow[t]{2}{*}{ Citizens } & 0.00 & 0.98 & 0.00 & 0.92 \\
\hline & $(0.00)$ & $(0.14)$ & $(0.00)$ & $(0.28)$ \\
\hline \multirow[t]{2}{*}{ Married } & 1.00 & 1.00 & 1.00 & 1.00 \\
\hline & $(0.00)$ & $(0.00)$ & $(0.00)$ & $(0.00)$ \\
\hline \multirow[t]{2}{*}{ age } & 40.14 & 44.09 & 36.57 & 36.37 \\
\hline & $(10.46)$ & $(11.37)$ & $(9.63)$ & $(9.80)$ \\
\hline \multirow[t]{2}{*}{ Male } & 0.69 & 0.44 & 0.50 & 0.50 \\
\hline & $(0.46)$ & $(0.50)$ & $(0.50)$ & $(0.50)$ \\
\hline \multirow[t]{2}{*}{ Foodstamps } & 0.05 & 0.06 & 0.12 & 0.09 \\
\hline & $(0.22)$ & $(0.25)$ & $(0.33)$ & $(0.29)$ \\
\hline \multirow[t]{2}{*}{ TANF } & 0.01 & 0.01 & 0.02 & 0.01 \\
\hline & $(0.12)$ & $(0.12)$ & $(0.13)$ & $(0.12)$ \\
\hline \multirow[t]{2}{*}{ Soc Sec } & 0.05 & 0.10 & 0.03 & 0.04 \\
\hline & $(0.22)$ & $(0.29)$ & $(0.17)$ & $(0.19)$ \\
\hline \multirow{2}{*}{ Supp Sec } & 0.01 & 0.02 & 0.01 & 0.02 \\
\hline & $(0.11)$ & $(0.15)$ & $(0.11)$ & $(0.13)$ \\
\hline \multirow[t]{2}{*}{ Any Transfer } & 0.10 & 0.16 & 0.15 & 0.13 \\
\hline & $(0.31)$ & $(0.37)$ & $(0.36)$ & $(0.34)$ \\
\hline \multirow[t]{2}{*}{ Employer Ins } & 0.77 & 0.84 & 0.63 & 0.78 \\
\hline & $(0.42)$ & $(0.36)$ & $(0.48)$ & $(0.41)$ \\
\hline \multirow[t]{2}{*}{ Private Ins } & 0.87 & 0.92 & 0.73 & 0.86 \\
\hline & $(0.34)$ & $(0.27)$ & $(0.44)$ & $(0.35)$ \\
\hline \multirow[t]{2}{*}{ Public Ins } & 0.15 & 0.18 & 0.21 & 0.15 \\
\hline & $(0.36)$ & $(0.38)$ & $(0.40)$ & $(0.36)$ \\
\hline \multirow[t]{2}{*}{ Purchased Ins } & 0.18 & 0.14 & 0.14 & 0.12 \\
\hline & $(0.38)$ & $(0.35)$ & $(0.34)$ & $(0.32)$ \\
\hline \multirow[t]{2}{*}{ Any Insurance } & 0.93 & 0.97 & 0.86 & 0.93 \\
\hline & $(0.25)$ & $(0.17)$ & $(0.34)$ & $(0.25)$ \\
\hline Observations & 4144 & 37968 & 161738 & 1564526 \\
\hline
\end{tabular}

This table reports means and standard deviations for demographic, transfer, and insurance variables. Each column represents individuals in a specific couple type: mixed-citizenship same-sex, same-citizenship samesex, mixed-citizenship different-sex, and same-citizenship different-sex. Data are from the 2012-2019 rounds of American Community Survey. 


\section{Table 6: Additional Individual-Level Summary Statistics - Married Individuals}

\begin{tabular}{|c|c|c|c|c|}
\hline & MSS & NSS & MDS & NDS \\
\hline & Mixed- & Same- & Mixed- & Same- \\
\hline & Citizenship & Citizenship & Citizenship & Citizenship \\
\hline & SS & SS & DS & DS \\
\hline \multirow[t]{2}{*}{ Survey Year } & $2,016.89$ & $2,016.72$ & $2,016.05$ & $2,016.12$ \\
\hline & $(1.73)$ & $(1.86)$ & $(2.22)$ & $(2.21)$ \\
\hline \multirow[t]{2}{*}{ year married } & $2,014.23$ & $2,013.57$ & $2,012.20$ & $2,011.98$ \\
\hline & $(2.29)$ & $(2.65)$ & $(2.81)$ & $(2.81)$ \\
\hline \multirow{2}{*}{$\begin{array}{l}1 \text { Born Abroad } \\
\text { Other Domestic }\end{array}$} & 0.74 & 0.09 & 0.56 & 0.07 \\
\hline & $(0.44)$ & $(0.29)$ & $(0.50)$ & $(0.25)$ \\
\hline \multirow[t]{2}{*}{ Interracial Couple } & 0.43 & 0.22 & 0.24 & 0.14 \\
\hline & $(0.50)$ & $(0.42)$ & $(0.43)$ & $(0.35)$ \\
\hline \multirow{2}{*}{$\begin{array}{l}1 \text { In School, } \\
\text { Other Out }\end{array}$} & 0.15 & 0.11 & 0.13 & 0.12 \\
\hline & $(0.36)$ & $(0.31)$ & $(0.34)$ & $(0.33)$ \\
\hline \multirow[t]{2}{*}{ Educ Gap $\geq 3$ Years } & 0.32 & 0.23 & 0.29 & 0.19 \\
\hline & $(0.47)$ & $(0.42)$ & $(0.45)$ & $(0.39)$ \\
\hline \multirow{2}{*}{ Age Gap $\geq 5$ Years } & 0.59 & 0.45 & 0.46 & 0.30 \\
\hline & $(0.49)$ & $(0.50)$ & $(0.50)$ & $(0.46)$ \\
\hline \multirow[t]{2}{*}{ Both Speak English Very Well } & 0.97 & 1.00 & 0.95 & 0.99 \\
\hline & $(0.16)$ & $(0.05)$ & $(0.23)$ & $(0.12)$ \\
\hline \multirow[t]{2}{*}{ Both University Educated } & 0.34 & 0.40 & 0.23 & 0.30 \\
\hline & $(0.47)$ & $(0.49)$ & $(0.42)$ & $(0.46)$ \\
\hline \multirow[t]{2}{*}{ Couple Moved between Country } & 0.00 & 0.00 & 0.01 & 0.01 \\
\hline & $(0.04)$ & $(0.05)$ & $(0.09)$ & $(0.08)$ \\
\hline \multirow[t]{2}{*}{ Couple Moved between States } & 0.02 & 0.03 & 0.03 & 0.03 \\
\hline & $(0.15)$ & $(0.16)$ & $(0.16)$ & $(0.18)$ \\
\hline \multirow[t]{2}{*}{ Couple Moved within State } & 0.11 & 0.10 & 0.15 & 0.14 \\
\hline & $(0.31)$ & $(0.30)$ & $(0.35)$ & $(0.35)$ \\
\hline \multirow[t]{2}{*}{ Couple Moved to a new State } & 0.02 & 0.03 & 0.04 & 0.04 \\
\hline & $(0.16)$ & $(0.17)$ & $(0.19)$ & $(0.19)$ \\
\hline \multirow[t]{2}{*}{1 Partner Abroad Last Year } & 0.01 & 0.00 & 0.04 & 0.00 \\
\hline & $(0.08)$ & $(0.07)$ & $(0.19)$ & $(0.07)$ \\
\hline \multirow[t]{2}{*}{ HH Income $>$ State Median } & 0.72 & 0.79 & 0.53 & 0.71 \\
\hline & $(0.45)$ & $(0.40)$ & $(0.50)$ & $(0.46)$ \\
\hline \multirow[t]{2}{*}{ Couple Owns Home } & 0.52 & 0.70 & 0.45 & 0.62 \\
\hline & $(0.50)$ & $(0.46)$ & $(0.50)$ & $(0.49)$ \\
\hline \multirow[t]{2}{*}{ Couple Has Kids } & 0.15 & 0.25 & 0.61 & 0.61 \\
\hline & $(0.35)$ & $(0.43)$ & $(0.49)$ & $(0.49)$ \\
\hline \multirow[t]{2}{*}{ HH Has $\geq 3$ Adults } & 0.18 & 0.12 & 0.14 & 0.08 \\
\hline & $(0.39)$ & $(0.32)$ & $(0.35)$ & $(0.27)$ \\
\hline \multirow[t]{2}{*}{ HH Has $\geq 5$ Bedrooms } & 0.15 & 0.23 & 0.17 & 0.25 \\
\hline & $(0.36)$ & $(0.42)$ & $(0.37)$ & $(0.43)$ \\
\hline Observations & 4144 & 37968 & 161738 & 1564526 \\
\hline
\end{tabular}

This table reports means and standard deviations for additional demographic variables. Each column represents individuals in a specific couple type: mixed-citizenship same-sex, same-citizenship same-sex, mixedcitizenship different-sex, and same-citizenship different-sex. Data are from the 2012-2019 rounds of American Community Survey. 


\section{A.3 Ancillary Results}

\section{A.3.1 Ancillary Regression Models}

I estimate a model similar to Equation (1), where groups are based on same-sex partnership and another household-level characteristic $Z_{g}$, as follows:

$$
\begin{aligned}
E\left[y_{g s t} \mid \mathbf{x}_{g s t}\right] & =\exp \left(\beta_{0}+\beta_{1} \text { post }_{t}+\beta_{2} Z_{g} \times \text { post }_{t}+\beta_{3} S S_{g} \times \text { post }_{t}\right. \\
& \left.+\beta_{4} Z_{g} \times S S_{g} \times \text { post }_{t}+\sigma_{g s}+\tau_{t}\right)
\end{aligned}
$$

Where $y_{g s t}$ is the number of individuals in group $g$, in state $s$, in year $t ; Z_{g}$ is an indicator variable for a household-level characteristic; $\mathrm{SS}_{g}$ is an indicator variable for same-sex couples; post $_{t}$ is an indicator variable for the post-period $t \geq 2013$, when married same-sex couples can access spousal visas; $\sigma_{g s}$ are group-state fixed effects; $\tau_{t}$ are year fixed effects; $t$ are survey years. $\beta_{4}$ is the coefficient of interest, representing the increase in the number of same-sex coupled individuals with $Z_{g}$ net of increases in same-sex couples without $Z_{g}$ and net of increases in different-sex couples with $Z_{g}$ over those without. $\beta_{4}$ represents the relative entry into same-sex couples of couples with characteristic $Z_{g}$. A non-zero $\beta_{4}$ could indicate a downstream effect of increased MSS couples, a mechanism through which MSS couples increase, differential selection into same-sex couples in the post-period, or a factor other than spousal visas that could explain their rise.

I also estimate a model with the right-hand-side of Equation (1) fully interacted with the new characteristic $Z_{g}$. This is a standard quadruple difference design, difference-indifferences-in-differences-in-differences, as follows:

$$
\begin{aligned}
& E\left[y_{g s t} \mid \mathbf{x}_{g s t}\right]=\exp \left(\beta_{0}+\beta_{1} \text { post }_{t}\right. \\
& +\beta_{2} Z_{g} \times \text { post }_{t}+\beta_{3} M_{g} \times \text { post }_{t}+\beta_{4} S S_{g} \times \text { post }_{t} \\
& +\beta_{5} Z_{g} \times M_{g} \times \text { post }_{t}+\beta_{6} Z_{g} \times S S_{g} \times \text { post }_{t}+\beta_{7} M_{g} \times S S_{g} \times \text { post }_{t} \\
& \left.+\beta_{8} Z_{g} \times M_{g} \times S S_{g} \times \text { post }_{t}+\sigma_{g s}+\tau_{t}\right)
\end{aligned}
$$

Where variables are defined above. The coefficient of interest is $\beta_{8}$ representing the increase in the number of mixed-citizenship same-sex coupled individuals with $Z_{g}$ net of increases in mixed-citizenship same-sex couples, in same-sex couples with $Z_{g}$, and mixed-citizenship couples with $Z_{g}$. $\beta_{8}$ represents the relative entry into MSS couples of couples with characteristic $Z_{g}$. A non-zero $\beta_{8}$ could indicate a downstream effect for MSS couples, a mechanism through which MSS couples increase, or differential selection into MSS couples in the post-period, or a factor other than spousal visas that could explain their rise. 
For heterogeneity analyses, I split the sample and run separate regressions. For state-level heterogeneity, I leave years unchanged. For birth country, age, and gender heterogeneity, the individual-level data within state-years are split. This increases the number of zeros and noise. To counter the noise, I combine years for these individual-level splits. 2008 and 2019 are unchanged; however, these pairs are combined into one: 2009/2010, 2011/2012, 2013/2014, 2015/2016, 2017/2018.

For heterogeneity by birth country, it is not interesting to consider same-citizenship couples because they are virtually all born in the United States. Therefore, I estimate Equation 4, but restrict the sample to individuals in mixed-citizenship couples only. In this case, $Z_{g}$ indicates a characteristic of the non-citizen's birth country.

Lastly, for naturalisation, I consider a group defined as "possibly naturalised through marriage", which indicates a couple is married, mixed-citizenship, and has been married and mixed-citizenship for at least three years. I order the couples by Survey Year to assess changes in the stock of naturalised coupled individuals and by Naturalisation Year to assess flow into naturalisation. The post period also changes: naturalizations can occur three years after marriage so, given time for paperwork, the first naturalizations due to same-sex marriage begin in 2017.

\section{A.3.2 Alternative Explanations}

The DDD design accounts for aggregate changes in both same-sex couples and mixedcitizenship couples. A credible explanation for the results must, therefore, explain why mixed-citizenship same-sex couples are differentially affected. For example, same-sex couples gain access to spousal visas but spousal visas matter to mixed-citizenship couples only, so mixed-citizenship same-sex couples are differentially affected. I explore a variety of alternatives. However, few alternatives offer a credible explanation for differential treatment of MSS couples and I find no evidence to support them.

Other federal transfer benefits and health insurance are incentives for couples to form and marry. However, including the number of couples with transfer benefits or health insurance in Columns 2 and 4 in Table 2 does not statistically significantly change the coefficients of interest; and MSS couples appear advantaged on some measures in Table 1. Moreover, robustness checks show no differential entry into same-sex coupling (Table 7) or MSS coupling (Table 8) by transfer receipt or by health insurance (Tables 9, 10).

Same-sex couples might move across states to access state-level marriage benefits. However, same-sex and MSS couples are not more likely to move across state lines or from abroad within the past year (Tables 11 and 12 ).

Many states legalised same-sex marriage in 2013, including California. However, results 
for early $(\leq 2012)$ and late (2015) legalisation states are statistically similar to each other and the main result (Table 13). Likewise, omitting California does not change the results (Table 14).

Contemporaneous changes to immigration policy, including the Deferred Action for Childhood Arrivals (DACA), made it easier for illegally present immigrants to adjust their immigration status. For non-residents, marrying a citizen requires an immigration status adjustment. However, there is little state-level heterogeneity by the non-citizen population share or by the illegally-present-immigrant non-citizen share (Table 13). (Estimates for illegally present immigrant numbers are from Van Hook et al. (2014).) There is also little heterogeneity by the non-citizen's partner birth country, including per capita income or longer visa wait-times (Table 15). Thus illegally present immigrants do not account for the results.

One limitation is unobserved stigma against same-sex couples, which fell during the study period. Stigma could lead to closeted cohabiting couples differentially responding as "roommates" in earlier years. However, the absolute change in unmarried same-sex tworoommate households cannot account for the main effect (Figure 3). Estimating Equation (1) on unmarried individuals in two-roommate households shows a slight upward trend in MSS roommates (Table 16) - the opposite of what could account for the main effect. Furthermore, the number of other adults in the household does not meaningfully change (Tables 17, 18).

Stigma against same-sex marriage could be stronger for non-citizens; and non-citizens could disproportionately decrease stigma after the Supreme Court confirms the legal rights of same-sex couples. Hence, one might expect greater entry into MSS couples by noncitizens from countries whose immigrant communities are most likely to update their beliefs. However, there is no change in relative entry into MSS couples by the legality of same-sex marriage in the non-citizen's birth country (Table 15). Although there is increased relative entry into MSS couples for those from countries with legal homosexuality. Neither result suggests a role for stigma.

Lastly, note that same-sex marriage legalisation does not impact different-sex marriage (Dillender, 2014; Carpenter, 2020). It is not the case that different-sex coupling changed or that it explains the main results.

\section{A.3.3 Mechanism}

Given the results and the institutional setting, I expect non-permanent residents to drive the results. Because removing restrictions on their marriages should increase their marriages; and removing pressure to dissolve from visa challenges should increase the stock of couples over time. I cannot test this mechanism directly, because visa or residency status is unobserved. Nevertheless, suggestive evidence supports this channel over others. 
Immigration policy has country specific visa caps and favours highly educated and high income immigrants. Therefore, visa trouble is likelier for those from specific countries and those with lower education. I find an increase in relative entry into MSS couples from countries with unique visa filing deadlines, which indicate longer waits (China, India, Mexico, Philippines) (Table 15); and that MSS couples are relatively more likely to have less than university education or above state median income (Table 18). These results are consistent with spousal visas helping MSS couples remain together in the face of visa uncertainty.

In this paper, couples form when they move in together. Consistent with couple formation, I find that same-sex and MSS couples are relatively more likely to both move within state (within the past year), but not across state lines (Table 12). Likewise, I do not find a significant increase in the relative incidence of MSS couples where exactly one partner was abroad last year. This suggests "mail order" spouses are not an important channel for spousal visas to increase couple formation and marriage.

Partners meet and date before moving in together. So moving in could reflect increased relative incidence of MSS dating or MSS couples that "live apart" deciding to live together. I do not observe when couples meet or how long they've dated. Therefore, I cannot distinguish between these two channels. However, it is unlikely that couples previously living apart account for the entire result for two reasons. First, Carpenter and Gates (2008) estimate that $10-11 \%$ of gay men and lesbian women have a same-sex partner but do not live together. If this proportion is similar for MSS and NSS couples and only MSS couples living apart moved in together, that would account for a third of the increase. Second, if MSS couples decide living apart is no longer worth it (maybe because a spousal visa gives them the flexibility to move or because living together is an implicit condition for a spousal visa), then they should move in relatively quickly. However, the relative incidence of MSS couples does not jump up, it slowly increases (Figure 1a).

Young people are more likely to be single and, therefore, can form couples and marry in larger proportions. I find the results are larger for those under 40 (Table 19).

It is unlikely marriage fraud drives the result because proving marriage for immigration purposes is difficult and proving same-sex marriage for immigration purposes can be more difficult, as mentioned in Section 1. Immigration officers can consider assortative mating in their decisions and can penalise large age gaps or interracial couples. I find that MSS couples become relatively more closely matched by age, but not race (Table 21). This is consistent with reduced partner search frictions for same-sex couples, especially at university or at work (Mansour and McKinnish, 2014). It is also inconsistent with an increase in mail order spouses.

Furthermore, the increase in marriages is driven by non-citizens who moved to the United 
States before 2013 (Table 22). This is inconsistent with marriage fraud as an important channel for the result. However, it is consistent with letting MSS couples marry and preventing their dissolution.

The point estimates for men are larger than those for women (Table 23). They are statistically different from each other for coupling, but not for marriage. It is unclear why this pattern emerges and exploring it is beyond the scope of this paper. Nevertheless, I speculate upon a technical explanation and three social explanations. First, despite combining years to avoid null counts, many observations are dropped. Hence, these heterogeneity results are not necessarily representative for women and men nationally. Second, geographic sorting: same-sex attracted men may live in areas with more non-citizens relative to same-sex attracted women. Third, differential stigma: same-sex attracted men may face greater stigma and higher (opportunity) costs relative to same-sex attracted women either abroad or in immigrant communities. Hence, men may differentially immigrate or leave their immigrant communities; and marrying a citizen can facilitate that. Fourth, barriers to reproduction: men face greater costs to having children together than women. Constrained from enjoying the benefits of children, male couples may benefit from other household public goods, which could be contingent upon an age gap.

\section{A.3.4 Downstream Outcomes}

The increase in MSS couples naturally increases the proportion of same-sex couples with the characteristics of MSS couples. Thus, more mixed-citizenship couples leads to an increase in disassortative mating by citizenship (36\%), birth country $(11 \%$, born domestically or abroad), and race (7\%), although the latter is insignificant (Table 20). There's also a $7 \%$ increase in the relative incidence of couples with an age gap less than five years.

The relative entry into MSS couples is greater for couples with some characteristics than others. Thus, spousal visa policy may favour certain couples or non-citizens. After 2013, the MSS couples are relatively more likely to have below state median income (11\%), no university education (14\%), and no children (6\%) (Table 18). However, this is consistent with two other findings. First, younger couples drive the effects (Table 19) and they have less income, education, and children. Second, same-sex couples are more positively selected on income and education than different-sex couples (Table 4). So decreases in income and education could mechanically reflect greater same-sex coupling. Furthermore, new MSS couples are just as likely to speak English "very well" or to "only speak English"; and non-citizen partners in new MSS couples are also relatively more likely to come from countries with unique visa filing deadlines, which indicate longer waits (China, India, Mexico, Philippines) (Table 15). This evidence suggests spousal visas differentially assist those who have difficulty 
getting other visas.

Lastly, assessing how spousal visa access leads to greater naturalisation is challenging because, more same-sex married couples can mechanically lead to more naturalizations for those with a same-sex spouse. It appears the number of new citizens married to a same-sex citizen for at least three years (the condition for spousal naturalisation) increases absolutely (Figure 8) and relative to other same-sex couples (Figure 9a). This is consistent with increases in same-sex marriage, but also consistent with increases in naturalizations resulting from greater access to spousal visas. 


\section{A.3.5 Federal Transfer Benefits}

Table 7 assesses relative entry into same-sex couples by federal transfer receipt.

Table 8 assesses relative entry into mixed-citizenship same-sex couples by federal transfer receipt.

\section{Table 7: DDD Estimates Where Groups are Based on Transfer Receipt}

\begin{tabular}{lccccc}
\hline \hline & Food Stamps & Welfare & Soc Sec & Supp Sec & Any \\
\hline post & -0.063 & -0.055 & -0.059 & -0.062 & -0.063 \\
& $(0.007)$ & $(0.007)$ & $(0.007)$ & $(0.007)$ & $(0.007)$ \\
postSSCT & -0.079 & 0.054 & 0.028 & -0.154 & -0.029 \\
& $(0.051)$ & $(0.067)$ & $(0.035)$ & $(0.061)$ & $(0.033)$ \\
postSSC & 0.391 & 0.384 & 0.381 & 0.387 & 0.389 \\
& $(0.020)$ & $(0.019)$ & $(0.019)$ & $(0.018)$ & $(0.021)$ \\
postCT & 0.053 & -0.179 & 0.013 & 0.177 & 0.026 \\
& $(0.028)$ & $(0.024)$ & $(0.008)$ & $(0.015)$ & $(0.014)$ \\
\hline Observations & 2448 & 2448 & 2448 & 2448 & 2448 \\
Log_Likelihood & -2508783.890 & $-858,099.669$ & $-721,516.550$ & $-914,537.507$ & -1993172.957 \\
Relative_IRR & 0.924 & 1.056 & 1.029 & 0.857 & 0.971 \\
Relative_IRR_se & 0.047 & 0.071 & 0.036 & 0.053 & 0.032 \\
IRR_pvalue & 0.108 & 0.431 & 0.424 & 0.007 & 0.367 \\
Chi2_Stat & 1.963 & 2.652 & 1.599 & 7.539 & 0.574 \\
p_value & 0.743 & 0.618 & 0.809 & 0.110 & 0.966 \\
\hline \hline
\end{tabular}

This table reports estimates for the effect of access to federal marriage benefits for same-sex couples on use of federal transfer benefits of same-sex couples. The benefits are are Food Stamps (SNAP), Welfare (TANF), Social Security, Supplemental Security Income, and Any Transfer (an indicator for any of the previous four). The relative incidence rate ratio (IRR) is the exponentiated coefficient of interest. The $\chi^{2}$ statistic is for a test of parallel pre-trends. Standard errors are clustered at the group-state level. Created using the 20082019 rounds of the American Community Survey. 


\section{Table 8: DDDD Estimates Where Groups are Based on Transfer Receipt}

\begin{tabular}{lccccc}
\hline \hline & Food Stamps & Welfare & Soc Sec & Supp Sec & Any \\
\hline post & -0.066 & -0.060 & -0.064 & -0.066 & -0.066 \\
postSSCT & $(0.006)$ & $(0.006)$ & $(0.007)$ & $(0.006)$ & $(0.007)$ \\
postSSC & -0.054 & 0.036 & 0.041 & -0.191 & -0.002 \\
& $(0.050)$ & $(0.069)$ & $(0.034)$ & $(0.061)$ & $(0.031)$ \\
postCT & 0.371 & 0.367 & 0.362 & 0.370 & 0.367 \\
& $(0.020)$ & $(0.019)$ & $(0.019)$ & $(0.018)$ & $(0.021)$ \\
postMC & 0.046 & -0.184 & 0.014 & 0.179 & 0.022 \\
& $(0.026)$ & $(0.024)$ & $(0.008)$ & $(0.014)$ & $(0.013)$ \\
postSSMC & 0.064 & 0.074 & 0.073 & 0.076 & 0.063 \\
& $(0.022)$ & $(0.016)$ & $(0.016)$ & $(0.015)$ & $(0.022)$ \\
postDCCT & 0.310 & 0.261 & 0.286 & 0.268 & 0.334 \\
postDDDD & $(0.061)$ & $(0.055)$ & $(0.055)$ & $(0.055)$ & $(0.061)$ \\
& 0.065 & 0.066 & 0.033 & -0.031 & 0.067 \\
Observations & $(0.055)$ & $(0.046)$ & $(0.029)$ & $(0.046)$ & $(0.034)$ \\
Log_Likelihood & -0.482 & 0.121 & -0.244 & -0.138 & -0.441 \\
Relative_IRR & -2843114.213 & -1102466.128 & -1007575.469 & -1162973.923 & -2343041.333 \\
Relative_IRR_se & 0.948 & 1.036 & 1.042 & 0.826 & 0.998 \\
IRR_pvalue & 0.047 & 0.071 & 0.036 & 0.050 & 0.031 \\
Chi2_Stat & 0.268 & 0.608 & 0.239 & 0.001 & 0.943 \\
p_value & 3.915 & 0.699 & 1.451 & 12.226 & 0.560 \\
\hline \hline
\end{tabular}

This table reports estimates for the effect of access to federal marriage benefits for same-sex couples on use of federal transfer benefits of mixed-citizenship same-sex couples. The benefits are are Food Stamps (SNAP), Welfare (TANF), Social Security, Supplemental Security Income, and Any Transfer (an indicator for any of the previous four). The relative incidence rate ratio (IRR) is the exponentiated coefficient of interest. The $\chi^{2}$ statistic is for a test of parallel pre-trends. Standard errors are clustered at the group-state level. Created using the 2008-2019 rounds of the American Community Survey. 


\section{A.3.6 Health Insurance}

Table 9 assesses relative entry into same-sex couples by health insurance type.

Table 10 assesses relative entry into mixed-citizenship same-sex couples by health insurance type.

\section{Table 9: DDD Estimates Where Groups are Based on Health In- surance}

\begin{tabular}{lccccc}
\hline \hline & Employer & Private & Public & Purchased & Any \\
\hline post & -0.062 & -0.169 & -0.101 & -0.068 & -0.450 \\
& $(0.006)$ & $(0.012)$ & $(0.010)$ & $(0.006)$ & $(0.050)$ \\
postSSCT & -0.007 & 0.080 & 0.009 & -0.081 & 0.111 \\
& $(0.031)$ & $(0.046)$ & $(0.044)$ & $(0.037)$ & $(0.095)$ \\
postSSC & 0.389 & 0.308 & 0.376 & 0.395 & 0.268 \\
& $(0.023)$ & $(0.040)$ & $(0.026)$ & $(0.018)$ & $(0.093)$ \\
postCT & 0.005 & 0.132 & 0.243 & 0.072 & 0.427 \\
& $(0.011)$ & $(0.015)$ & $(0.024)$ & $(0.020)$ & $(0.051)$ \\
\hline Observations & 2436 & 2412 & 2448 & 2448 & 2335 \\
Log_Likelihood & -1120801.266 & -1523743.429 & -1535073.692 & -1231566.714 & -2402064.358 \\
Relative_IRR & 0.993 & 1.083 & 1.009 & 0.922 & 1.117 \\
Relative_IRR_se & 0.031 & 0.049 & 0.045 & 0.034 & 0.106 \\
IRR_pvalue & 0.826 & 0.091 & 0.836 & 0.021 & 0.267 \\
Chi2_Stat & 0.634 & 0.856 & 8.448 & 0.850 & 2.529 \\
p_value & 0.959 & 0.931 & 0.076 & 0.932 & 0.639 \\
\hline \hline
\end{tabular}

This table reports estimates for the effect of access to federal marriage benefits for same-sex couples on the type of health insurance owned by same-sex couple. Health insurance could be from an Employer, it could be Private or Public, it could be Purchased, or it could be any health insurance. The relative incidence rate ratio (IRR) is the exponentiated coefficient of interest. The $\chi^{2}$ statistic is for a test of parallel pre-trends. Standard errors are clustered at the group-state level. Created using the 2008-2019 rounds of the American Community Survey. 


\section{Table 10: DDDD Estimates Where Groups are Based on Health Insurance}

\begin{tabular}{lccccc}
\hline \hline & Employer & Private & Public & Purchased & Any \\
\hline post & -0.069 & -0.178 & -0.103 & -0.071 & -0.453 \\
postSSCT & $(0.006)$ & $(0.011)$ & $(0.009)$ & $(0.006)$ & $(0.046)$ \\
& -0.018 & 0.063 & 0.036 & -0.080 & 0.121 \\
postSSC & $(0.033)$ & $(0.047)$ & $(0.040)$ & $(0.035)$ & $(0.097)$ \\
& 0.381 & 0.307 & 0.353 & 0.378 & 0.243 \\
postCT & $(0.025)$ & $(0.041)$ & $(0.025)$ & $(0.018)$ & $(0.095)$ \\
& 0.009 & 0.135 & 0.231 & 0.061 & 0.423 \\
postMC & $(0.010)$ & $(0.014)$ & $(0.021)$ & $(0.018)$ & $(0.046)$ \\
& 0.075 & 0.071 & 0.035 & 0.049 & 0.026 \\
postSSMC & $(0.015)$ & $(0.025)$ & $(0.033)$ & $(0.016)$ & $(0.101)$ \\
& 0.075 & 0.051 & 0.349 & 0.243 & 0.253 \\
postDCCT & $(0.062)$ & $(0.100)$ & $(0.068)$ & $(0.063)$ & $(0.173)$ \\
postDDDD & 0.002 & 0.032 & 0.174 & 0.202 & 0.102 \\
& $(0.030)$ & $(0.037)$ & $(0.059)$ & $(0.059)$ & $(0.103)$ \\
\hline Observations & 0.286 & 0.294 & -0.372 & -0.012 & 0.042 \\
Log_Likelihood & -1477808.502 & -1882863.639 & -1879171.728 & -1575632.120 & -2773497.924 \\
Relative_IRR & 0.982 & 1.065 & 1.037 & 0.923 & 1.129 \\
Relative_IRR_se & 0.032 & 0.050 & 0.042 & 0.033 & 0.110 \\
IRR_pvalue & 0.567 & 0.194 & 0.376 & 0.018 & 0.241 \\
Chi2_Stat & 0.169 & 0.864 & 5.511 & 1.583 & 6.347 \\
p_value & 0.997 & 0.930 & 0.239 & 0.812 & 0.175 \\
\hline
\end{tabular}

This table reports estimates for the effect of access to federal marriage benefits for same-sex couples on the type of health insurance owned by mixed-citizenship same-sex couples. Health insurance could be from an Employer, it could be Private or Public, it could be Purchased, or it could be any health insurance. The relative incidence rate ratio (IRR) is the exponentiated coefficient of interest. The $\chi^{2}$ statistic is for a test of parallel pre-trends. Standard errors are clustered at the group-state level. Created using the 2008-2019 rounds of the American Community Survey. 


\section{A.3.7 Moved Recently}

Table 11 assesses relative entry into same-sex couples by recent moves (within the past year).

Table 12 assesses relative entry into mixed-citizenship same-sex couples by recent moves (within the past year).

\section{Table 11: DDD Estimates Where Groups are Based on Moving within the Past Year}

\begin{tabular}{lccccc}
\hline \hline & Abroad & Different State & Within State & Abroad or Diff State & One Abroad \\
\hline post & -0.059 & -0.060 & -0.057 & -0.060 & -0.057 \\
& $(0.006)$ & $(0.006)$ & $(0.008)$ & $(0.006)$ & $(0.007)$ \\
postSSCT & 0.199 & -0.009 & 0.115 & -0.000 & 0.053 \\
& $(0.220)$ & $(0.056)$ & $(0.046)$ & $(0.050)$ & $(0.111)$ \\
postSSC & 0.384 & 0.383 & 0.370 & 0.383 & 0.383 \\
& $(0.018)$ & $(0.018)$ & $(0.018)$ & $(0.018)$ & $(0.018)$ \\
postCT & 0.213 & 0.105 & -0.005 & 0.114 & -0.116 \\
& $(0.032)$ & $(0.016)$ & $(0.025)$ & $(0.017)$ & $(0.029)$ \\
\hline Observations & 2212 & 2436 & 2448 & 2436 & 2313 \\
Log_Likelihood & $-579,499.685$ & $-664,517.358$ & $-835,784.587$ & $-671,941.929$ & $-590,041.600$ \\
Relative_IRR & 1.221 & 0.991 & 1.122 & 1.000 & 1.054 \\
Relative_IRR_se & 0.269 & 0.056 & 0.051 & 0.050 & 0.117 \\
IRR_pvalue & 0.412 & 0.874 & 0.018 & 0.997 & 0.644 \\
Chi2_Stat & 17.741 & 1.418 & 1.311 & 1.100 & 2.186 \\
p_value & 0.001 & 0.841 & 0.859 & 0.894 & 0.702 \\
\hline \hline
\end{tabular}

This table reports estimates for the effect of access to federal marriage benefits for same-sex couples on the likelihood same-sex couples moved within the past year. Couples could both move from abroad (Abroad), from another state (Different State), within their state of residence (Within State), either from abroad or from another state (Abroad or Diff State), or exactly one partner moved from abroad (One Abroad). The relative incidence rate ratio (IRR) is the exponentiated coefficient of interest. The $\chi^{2}$ statistic is for a test of parallel pre-trends. Standard errors are clustered at the group-state level. Created using the 2008-2019 rounds of the American Community Survey. 


\section{Table 12: DDDD Estimates Where Groups are Based on Moving within the Past Year}

\begin{tabular}{lccccc}
\hline \hline & Abroad & Different State & Within State & Abroad or Diff State & One Abroad \\
\hline post & -0.063 & -0.064 & -0.063 & -0.065 & -0.062 \\
postSSCT & $(0.006)$ & $(0.006)$ & $(0.007)$ & $(0.006)$ & $(0.006)$ \\
& 0.031 & -0.046 & 0.117 & -0.031 & 0.094 \\
postSSC & $(0.202)$ & $(0.056)$ & $(0.045)$ & $(0.052)$ & $(0.098)$ \\
& 0.367 & 0.366 & 0.352 & 0.366 & 0.367 \\
postCT & $(0.018)$ & $(0.018)$ & $(0.018)$ & $0.018)$ & $(0.018)$ \\
& 0.243 & 0.111 & 0.003 & 0.122 & -0.208 \\
postMC & $(0.033)$ & $(0.016)$ & $(0.022)$ & $(0.017)$ & $(0.037)$ \\
& 0.075 & 0.076 & 0.088 & 0.077 & 0.074 \\
postSSMC & $(0.015)$ & $(0.015)$ & $(0.015)$ & $0.015)$ & $(0.015)$ \\
& 0.265 & 0.270 & 0.276 & $(0.054)$ & 0.271 \\
postDCCT & $(0.054)$ & $(0.054)$ & $(0.057)$ & -0.127 & $(0.056)$ \\
postDDDD & -0.297 & -0.100 & -0.120 & $(0.046)$ & 0.226 \\
& $(0.074)$ & $(0.053)$ & $(0.058)$ & -0.201 & $(0.049)$ \\
Observations & -0.245 & -0.194 & -0.097 & $(0.249)$ & -0.550 \\
Log_Likelihood & $-796,584.151$ & $-929,417.740$ & -1149815.737 & $-942,380.444$ & $-823,485.534$ \\
Relative_IRR & 1.031 & 0.955 & 1.125 & 0.970 & 1.098 \\
Relative_IRR_se & 0.208 & 0.054 & 0.051 & 0.050 & 0.108 \\
IRR_pvalue & 0.881 & 0.407 & 0.014 & 0.547 & 0.361 \\
Chi2_Stat &. & 3.900 & 1.554 & 3.887 & 2.779 \\
p_value &. & 0.420 & 0.817 & 0.421 & 0.595 \\
\hline \hline
\end{tabular}

This table reports estimates for the effect of access to federal marriage benefits for same-sex couples on the likelihood mixed-citizenship same-sex couples moved within the past year. Couples could both move from abroad (Abroad), from another state (Different State), within their state of residence (Within State), either from abroad or from another state (Abroad or Diff State), or exactly one partner moved from abroad (One Abroad). The relative incidence rate ratio (IRR) is the exponentiated coefficient of interest. The $\chi^{2}$ statistic is for a test of parallel pre-trends. Standard errors are clustered at the group-state level. Created using the 2008-2019 rounds of the American Community Survey. 


\section{A.3.8 State-Level Heterogeneity}

\section{Table 13: Heterogeneity by State - DDD Estimates Restricted by State}

\begin{tabular}{lcccccc}
\hline \hline & \multicolumn{2}{c}{ SSM Legalized } & \multicolumn{2}{c}{ Non-Citizen Share } & \multicolumn{2}{c}{ Unauthorized Share } \\
& Early & Late & High & Low & High & Low \\
\hline post & -0.089 & -0.053 & -0.078 & -0.053 & -0.075 & -0.051 \\
& $(0.008)$ & $(0.016)$ & $(0.003)$ & $(0.009)$ & $(0.006)$ & $(0.008)$ \\
postSSCT & 0.248 & 0.494 & 0.229 & 0.329 & 0.274 & 0.335 \\
& $(0.068)$ & $(0.156)$ & $(0.108)$ & $(0.060)$ & $(0.045)$ & $(0.094)$ \\
postSSC & 0.333 & 0.425 & 0.408 & 0.348 & 0.353 & 0.382 \\
& $(0.018)$ & $(0.037)$ & $(0.018)$ & $(0.024)$ & $(0.015)$ & $(0.034)$ \\
postCT & 0.051 & 0.119 & 0.127 & 0.059 & 0.071 & 0.075 \\
& $(0.012)$ & $(0.018)$ & $(0.011)$ & $(0.018)$ & $(0.014)$ & $(0.024)$ \\
\hline Observations & 336 & 576 & 1248 & 1200 & 1248 & 1200 \\
Log_Likelihood & $-79,646$ & $-167,188$ & $-255,385$ & $-388,900$ & $-330,918$ & $-312,695$ \\
Relative_IRR & 1.281 & 1.638 & 1.258 & 1.389 & 1.315 & 1.398 \\
Relative_IRR_se & 0.087 & 0.255 & 0.136 & 0.083 & 0.059 & 0.131 \\
IRR_pvalue & 0.001 & 0.012 & 0.058 & 0.000 & 0.000 & 0.002 \\
Pre_Trend & 12.807 & 38.802 & 1.449 & 5.856 & 3.753 & 29.934 \\
p_value & 0.012 & 0.000 & 0.836 & 0.210 & 0.440 & 0.000 \\
\hline
\end{tabular}

This table reports estimates for the effect of access to federal marriage benefits for same-sex couples on mixedcitizenship same-sex coupling, by different state categories. States are split based on same-sex marriage (SSM) legalisation timing, the proportion of people that are non-citizens, and the proportion of non-citizens that are illegally present. The relative incidence rate ratio (IRR) is the exponentiated coefficient of interest. The $\chi^{2}$ statistic is for a test of parallel pre-trends. Standard errors are clustered at the group-state level. Created using the 2008-2019 rounds of the American Community Survey. 


\section{A.3.9 Main Result without California}

\section{Table 14: DDD Estimates for the Main Specification without Cal- ifornia}

\begin{tabular}{lc}
\hline \hline & Coupled Individuals \\
\hline post & -0.064 \\
& $(0.007)$ \\
postSSCT & 0.286 \\
& $(0.067)$ \\
postSSC & 0.379 \\
& $(0.018)$ \\
postCT & 0.087 \\
& $(0.015)$ \\
\hline Observations & 2400 \\
Log_Likelihood & $-636,561.610$ \\
Relative_IRR & 1.331 \\
Relative_IRR_se & 0.090 \\
IRR_pvalue & 0.000 \\
Pre_Trend & 1.927 \\
p_value & 0.749 \\
\hline \hline
\end{tabular}

This table reports the Poisson Conditional Fixed Effects estimates for Equation (1). SS refers to same-sex coupled individuals and $\mathrm{M}$ refers to mixed-citizenship coupled individuals. The coefficient of interest is post $\times \mathrm{SS} \times \mathrm{M}$ and the Relative Incidence Rate Ratio (IRR) is the exponentiated coefficient of interest. The $\chi^{2}$ pre-trend test reports the test statistic for the test of parallel pre-trends, described by Equation (3). Standard errors in parentheses, clustered at the group-state level. Created using the 2008-2019 rounds of the American Community Survey. 


\section{A.3.10 Birth Country Heterogeneity}

\section{Table 15: Heterogeneity by Birth Country - DDD Estimates Re- stricted by Birth Country}

\begin{tabular}{lcccc}
\hline \hline & SSM Legal & Gay Legal & Longer Visa Waits & Low Income \\
\hline post & 0.037 & 0.092 & -0.017 & -0.112 \\
postSSCT & $(0.018)$ & $(0.048)$ & $(0.018)$ & $(0.011)$ \\
& 0.007 & 0.557 & 0.202 & 0.115 \\
postSSC & $(0.089)$ & $(0.174)$ & $(0.088)$ & $(0.094)$ \\
& 0.710 & 0.189 & 0.640 & 0.632 \\
postCT & $(0.058)$ & $(0.168)$ & $(0.061)$ & $(0.071)$ \\
& -0.154 & -0.085 & 0.072 & 0.153 \\
\hline Observations & $(0.021)$ & $(0.050)$ & $(0.027)$ & $(0.022)$ \\
Log_Likelihood & $-151,145.507$ & $-159,719.192$ & $-170,564.441$ & $-156,520.554$ \\
Relative_IRR & 1.007 & 1.746 & 1.224 & 1.121 \\
Relative_IRR_se & 0.089 & 0.304 & 0.108 & 0.105 \\
IRR_pvalue & 0.940 & 0.014 & 0.038 & 0.249 \\
Chi2_Stat & 0.056 & 6.256 & 2.510 & 0.875 \\
p_value & 0.972 & 0.044 & 0.285 & 0.646 \\
\hline \hline
\end{tabular}

This table reports estimates for the effect of access to federal marriage benefits for same-sex couples on differential mixed-citizenship same-sex coupling, by birth country categories. The sample is necessarily restricted to mixed-citizenship couples only. Countries are split based on the legality of same-sex marriage (SSM Legal), the legality of homosexuality (Gay Legal), special filing deadlines related to some visas (Longer Visa Waits), and PPP adjusted GNP (Low Income). The relative incidence rate ratio (IRR) is the exponentiated coefficient of interest. The $\chi^{2}$ statistic is for a test of parallel pre-trends. Standard errors are clustered at the group-state level. Created using the 2008-2019 rounds of the American Community Survey. 


\section{A.3.11 Same-Sex Roommates}

Figure 3 shows the number of individuals in two-roommate households, grouped by same-sex and mixed-citizenship. The numbers are stable over time, suggesting there is no relabelling from same-sex roommates to same-sex couples, and that relabelling does not explain the estimated effect size. Specifically, there are 123695 mixed-citizenship same-sex roommates in 2008 and 128823 in 2019, ranging between 115524 and 135070 across the twelve years. Whereas in Figure 1a, there are 38819 mixed-citizenship same-sex couples in 2008 and 109 781 in 2019, an increase of nearly 70000 for which roommate numbers cannot account.

Table 16 shows the number of mixed-citizenship same-sex roommates increased by $8.7 \%$ in the post-period, rather than fell. However, the effect is statistically insignificant and the hypothesis of parallel pre-trends is rejected at the $10 \%$ level.

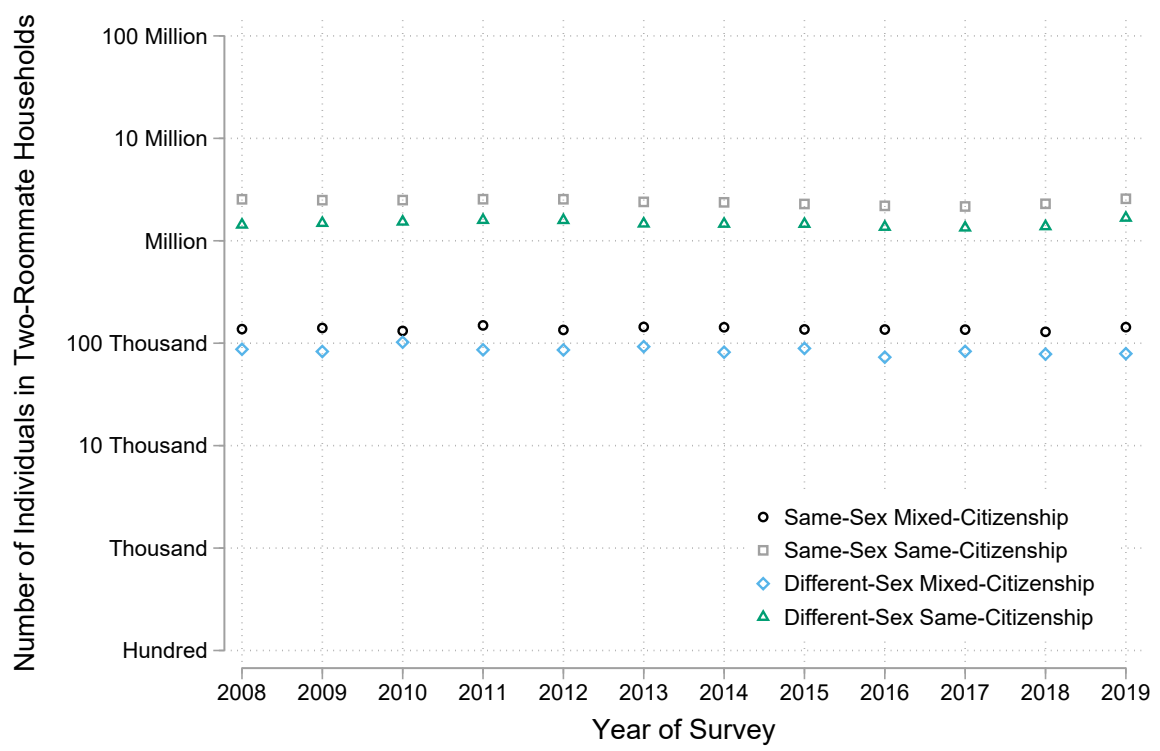

\section{Figure 3: Number of Individuals in a Two-Roommate Household, by Survey Year}

Each point is the population estimate for the number of individuals in a given roommate type and year, representative of the United States population in the given year. The vertical axis depicts the number of individuals on a logarithmic scale. The horizontal axis depicts years. The four roommate types are determined by the intersection of same- or different-sex and same- or mixed-citizenship. The sample is restricted to roommates in households with exactly two adults. Created using the 2008-2019 rounds of the American Community Survey. 


\section{Table 16: DDD Estimates for Roommates}

\begin{tabular}{lc}
\hline \hline & Roommates \\
\hline post & -0.064 \\
& $(0.016)$ \\
postSSCT & 0.083 \\
& $(0.058)$ \\
postSSC & -0.031 \\
& $(0.020)$ \\
postCT & 0.058 \\
& $(0.045)$ \\
\hline Observations & 2321 \\
Log_Likelihood & $-566,078.362$ \\
Relative_IRR & 1.087 \\
Relative_IRR_se & 0.063 \\
IRR_pvalue & 0.167 \\
Pre_Trend & 9.425 \\
p_value & 0.051 \\
\hline \hline
\end{tabular}

This table reports estimates for the effect of access to federal marriage benefits for same-sex couples on the number of mixed-citizenship same-sex roommates. The relative incidence rate ratio (IRR) is the exponentiated coefficient of interest. The $\chi^{2}$ statistic is for a test of parallel pre-trends. Standard errors are clustered at the group-state level. Created using the 2008-2019 rounds of the American Community Survey. 


\section{A.3.12 Household Characteristics}

Table 17 assesses relative entry into same-sex couples by household characteristics.

Table 18 assesses relative entry into mixed-citizenship same-sex couples by household characteristics.

\section{Table 17: DDD Estimates Where Groups are Based on Household Characteristics}

\begin{tabular}{lccccc}
\hline \hline & High Income & Good English & High Educ & Has Kids & Extra Adults \\
\hline post & -0.065 & -0.011 & -0.102 & -0.046 & -0.062 \\
& $(0.008)$ & $(0.017)$ & $(0.007)$ & $(0.005)$ & $(0.007)$ \\
postSSCT & -0.112 & 0.008 & -0.149 & -0.060 & -0.020 \\
& $(0.029)$ & $(0.052)$ & $(0.029)$ & $(0.033)$ & $(0.036)$ \\
postSSC & 0.467 & 0.379 & 0.416 & 0.390 & 0.385 \\
& $(0.021)$ & $(0.049)$ & $(0.020)$ & $(0.018)$ & $(0.018)$ \\
postCT & 0.010 & -0.054 & 0.186 & -0.019 & 0.044 \\
& $(0.010)$ & $(0.019)$ & $(0.010)$ & $(0.009)$ & $(0.011)$ \\
\hline Observations & 2441 & 2319 & 2448 & 2448 & 2448 \\
Log_Likelihood & $-671,654.483$ & $-718,781.086$ & -1057152.589 & $-661,740.217$ & $-694,506.327$ \\
Relative_IRR & 0.894 & 1.008 & 0.862 & 0.942 & 0.980 \\
Relative_IRR_se & 0.025 & 0.053 & 0.025 & 0.031 & 0.035 \\
IRR_pvalue & 0.000 & 0.884 & 0.000 & 0.059 & 0.568 \\
Chi2_Stat & 2.402 & 10.297 & 7.520 & 6.756 & 4.959 \\
p_value & 0.662 & 0.036 & 0.111 & 0.149 & 0.292 \\
\hline \hline
\end{tabular}

This table reports estimates for the effect of access to federal marriage benefits for same-sex couples on household characteristics of same-sex couples. Household characteristics are: above state-year median income (High Inc), both partners speak English, either "very well" or "only speaks english" (Good English), both partners have a Bachelor's degree (High Educ), children are present in the household (Has Kids), or the presence of other adults in the household (Extra Adults). The relative incidence rate ratio (IRR) is the exponentiated coefficient of interest. The $\chi^{2}$ statistic is for a test of parallel pre-trends. Standard errors are clustered at the group-state level. Created using the 2008-2019 rounds of the American Community Survey. 


\section{Table 18: DDDD Estimates Where Groups are Based on Household Characteristics}

\begin{tabular}{lccccc}
\hline \hline & High Income & Good English & High Educ & Has Kids & Extra Adults \\
\hline post & -0.075 & -0.017 & -0.109 & -0.051 & -0.067 \\
postSSCT & $(0.008)$ & $(0.018)$ & $(0.007)$ & $(0.004)$ & $(0.006)$ \\
& -0.123 & 0.112 & -0.154 & -0.029 & -0.035 \\
postSSC & $(0.028)$ & $(0.059)$ & $(0.030)$ & $(0.033)$ & $(0.037)$ \\
& 0.459 & 0.261 & 0.401 & 0.366 & 0.369 \\
postCT & $(0.020)$ & $(0.056)$ & $(0.020)$ & $(0.017)$ & $(0.018)$ \\
& 0.018 & -0.050 & 0.192 & -0.019 & 0.048 \\
postMC & $(0.010)$ & $(0.019)$ & $(0.010)$ & $(0.009)$ & $(0.010)$ \\
& 0.103 & 0.026 & 0.101 & 0.103 & 0.083 \\
postSSMC & $0.012)$ & $(0.025)$ & $(0.016)$ & $(0.017)$ & $(0.016)$ \\
& 0.049 & 0.290 & 0.207 & 0.341 & 0.248 \\
postDCCT & $(0.085)$ & $(0.096)$ & $(0.064)$ & $(0.064)$ & $(0.063)$ \\
& -0.046 & 0.056 & -0.079 & -0.039 & -0.070 \\
postDDDD & $(0.025)$ & $(0.031)$ & $(0.025)$ & $(0.024)$ & $(0.028)$ \\
& 0.306 & 0.010 & 0.136 & -0.481 & 0.098 \\
\hline Observations & $(0.103)$ & $(0.118)$ & $(0.092)$ & $(0.112)$ & $(0.117)$ \\
Log_Likelihood & -1026423.112 & -1062284.248 & -1389133.655 & -1017926.763 & -1022319.468 \\
Relative_IRR & 0.884 & 1.119 & 0.857 & 0.971 & 0.966 \\
Relative_IRR_se & 0.025 & 0.065 & 0.026 & 0.032 & 0.036 \\
IRR_pvalue & 0.000 & 0.069 & 0.000 & 0.374 & 0.344 \\
Chi2_Stat & 2.832 & 10.272 & 8.742 & 8.999 & 3.815 \\
p_value & 0.586 & 0.036 & 0.068 & 0.061 & 0.432 \\
\hline \hline
\end{tabular}

This table reports estimates for the effect of access to federal marriage benefits for same-sex couples on household characteristics of mixed-citizenship same-sex couples. Household characteristics are: above stateyear median income (High Inc), both partners speak English, either "very well" or "only speaks english" (Good English), both partners have a Bachelor's degree (High Educ), children are present in the household (Has Kids), or the presence of other adults in the household (Extra Adults). The relative incidence rate ratio (IRR) is the exponentiated coefficient of interest. The $\chi^{2}$ statistic is for a test of parallel pre-trends. Standard errors are clustered at the group-state level. Created using the 2008-2019 rounds of the American Community Survey. 


\section{A.3.13 Age Heterogeneity}

\section{Table 19: Heterogeneity by Age - DDD Estimates Restricted by Age}

\begin{tabular}{lcccc}
\hline \hline & \multicolumn{2}{c}{ Coupled Individuals } & \multicolumn{2}{c}{ Married Individuals } \\
& Older & Younger & Older & Younger \\
\hline post & -0.079 & -0.883 & -0.058 & -0.762 \\
& $(0.006)$ & $(0.007)$ & $(0.009)$ & $(0.011)$ \\
post $\times$ SameSexDiffCiti & 0.354 & 0.693 & 0.264 & 0.527 \\
& $(0.062)$ & $(0.152)$ & $(0.069)$ & $(0.323)$ \\
post $\times$ SameSexCouple & 0.535 & 1.418 & 0.304 & 1.179 \\
& $(0.022)$ & $(0.128)$ & $(0.021)$ & $(0.277)$ \\
post $\times$ CitizenshipType & 0.024 & 0.136 & 0.134 & 0.238 \\
& $(0.018)$ & $(0.018)$ & $(0.021)$ & $(0.025)$ \\
\hline Observations & 1421 & 1380 & 1414 & 1349 \\
Log_Likelihood & $-297,114.401$ & -7360356.187 & $-258,817.416$ & -2781468.454 \\
Relative_IRR & 1.425 & 2.000 & 1.302 & 1.694 \\
Relative_IRR_se & 0.089 & 0.303 & 0.090 & 0.546 \\
IRR_pvalue & 0.000 & 0.001 & 0.001 & 0.204 \\
Pre_Trend & 0.649 & 4.378 & 2.684 & 1.877 \\
p_value & 0.723 & 0.112 & 0.261 & 0.391 \\
\hline \hline
\end{tabular}

This table reports the Poisson Conditional Fixed Effects estimates for Equation (1). SS refers to same-sex coupled individuals and $\mathrm{M}$ refers to mixed-citizenship coupled individuals. The coefficient of interest is post $\times \mathrm{SS} \times \mathrm{M}$ and the Relative Incidence Rate Ratio (IRR) is the exponentiated coefficient of interest. The $\chi^{2}$ pre-trend test reports the test statistic for the test of parallel pre-trends, described by Equation (3). Standard errors in parentheses, clustered at the group-state level. Created using the American Community Survey. Columns 1 and 3, with coupled individuals, uses the 2008-2019 rounds. Columns 2 and 4, with married individuals only, uses the 2012-2019 rounds. 


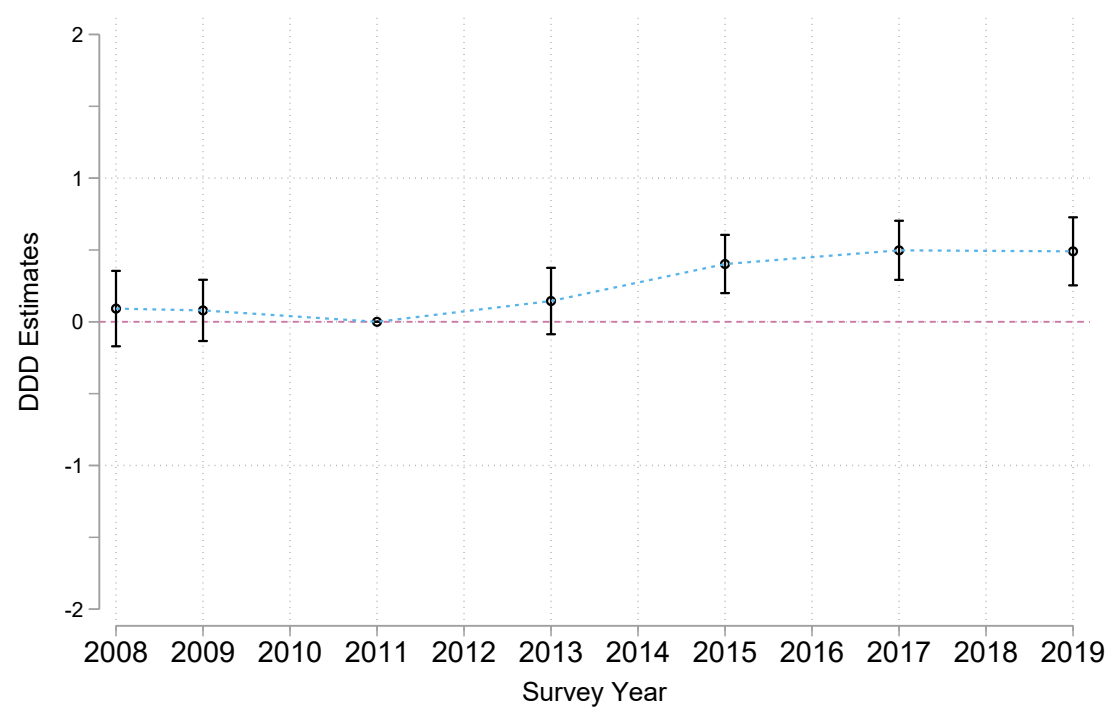

(a) Young Coupled Individuals by Survey Year

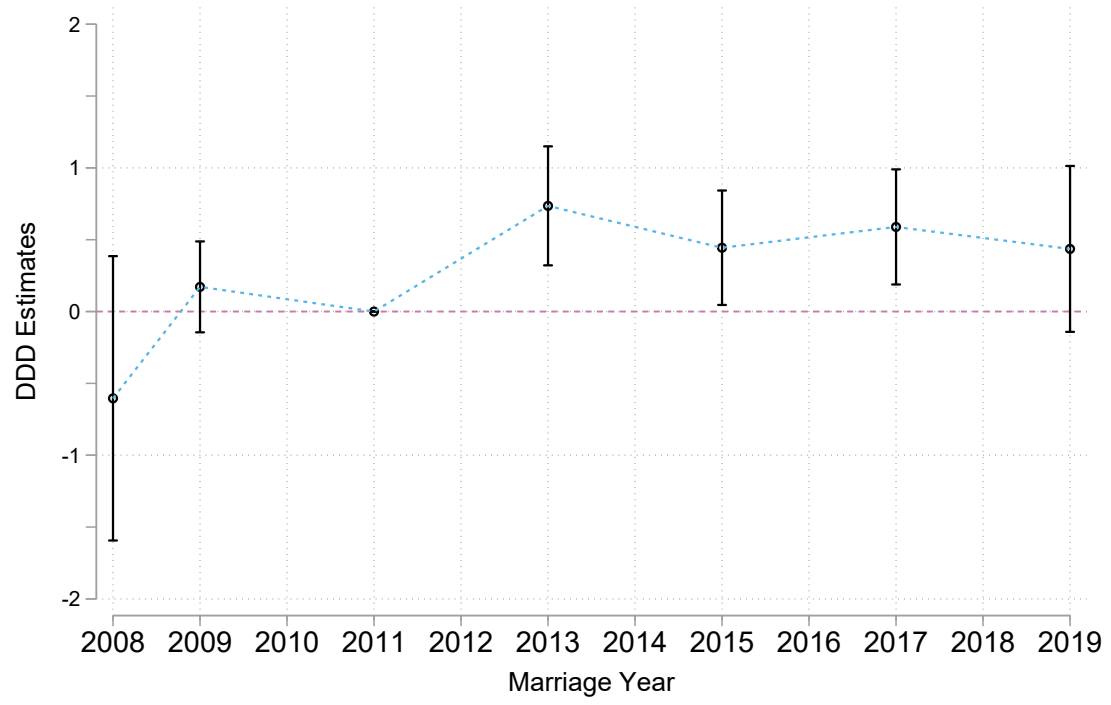

(b) Young Married Couples by Marriage Year

\section{Figure 4: Dynamic DDD Estimates for Young Couples}

This figure plots the Poisson Conditional Fixed Effects estimates for Equation (2), where time is either Survey Year or Marriage Year. The sample is restricted to individuals younger than 40 only. Standard errors are clustered at the group-state level. Data are from the American Community Survey. The first subfigure uses the 2008-2019 rounds; the second subfigure uses the 2012-2019 rounds. 


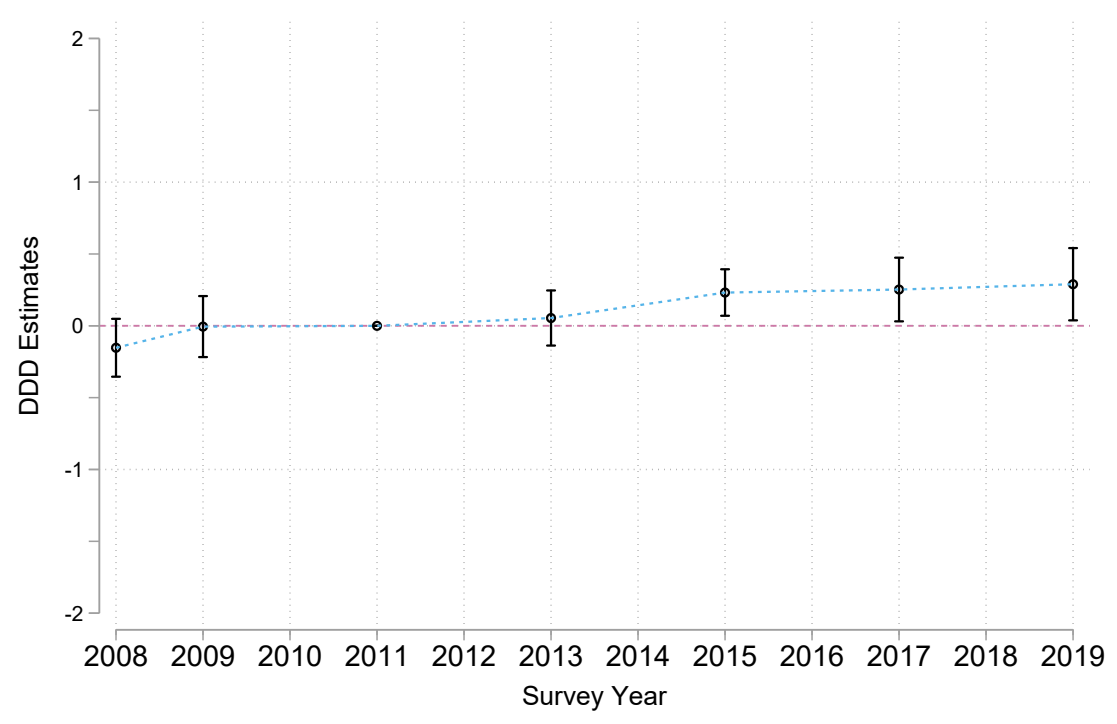

(a) Old Coupled Individuals by Survey Year

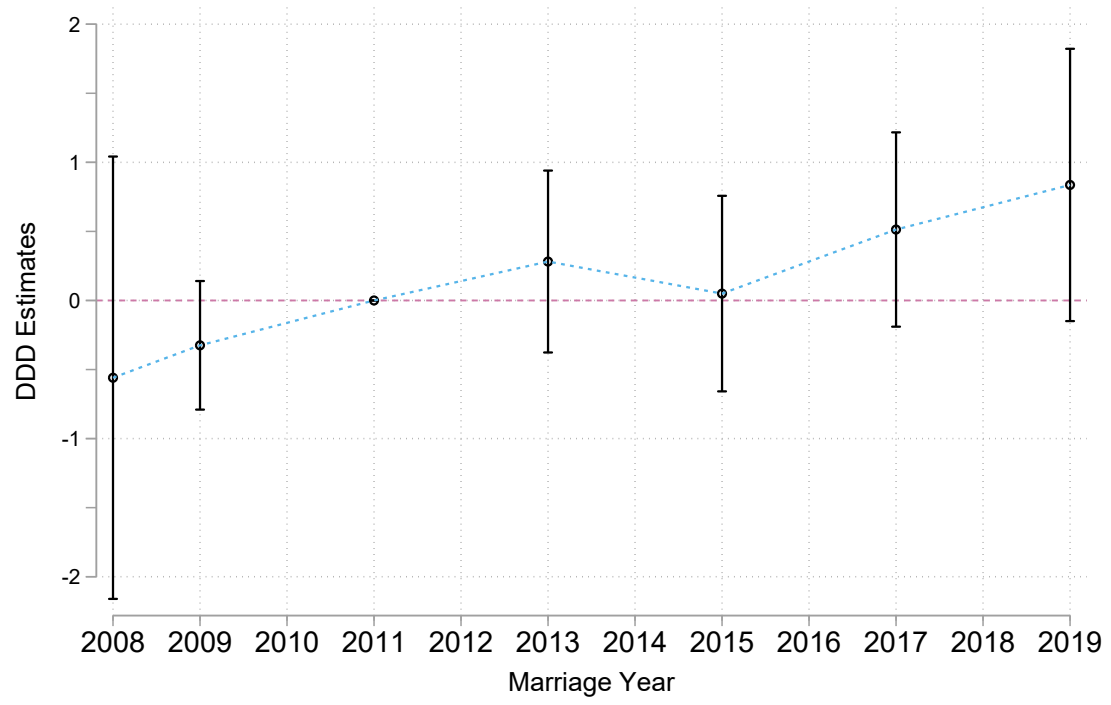

(b) Old Married Couples by Marriage Year

\section{Figure 5: Dynamic DDD Estimates for Old Couples}

This figure plots the Poisson Conditional Fixed Effects estimates for Equation (2), where time is either Survey Year or Marriage Year. The sample is restricted to individuals 40 or older only. Standard errors are clustered at the group-state level. Data are from the American Community Survey. The first subfigure uses the 2008-2019 rounds; the second subfigure uses the 2012-2019 rounds. 


\section{A.3.14 Disassortativeness}

Table 20 assesses relative entry into same-sex couples by a type of disassortative mating.

Table 21 assesses relative entry into mixed-citizenship same-sex couples by a type of disassortative mating.

\section{Table 20: DDD Estimates Where Groups are Based on Disassorta- tiveness Measures}

\begin{tabular}{lccccc}
\hline \hline & Birthplace & Race & Student & Education & Age \\
\hline post & -0.068 & -0.077 & -0.047 & -0.063 & -0.050 \\
& $(0.006)$ & $(0.006)$ & $(0.006)$ & $(0.007)$ & $(0.007)$ \\
postSSCT & 0.101 & 0.068 & -0.026 & -0.047 & -0.076 \\
& $(0.046)$ & $(0.046)$ & $(0.038)$ & $(0.031)$ & $(0.029)$ \\
postSSC & 0.369 & 0.350 & 0.393 & 0.394 & 0.424 \\
& $(0.017)$ & $(0.017)$ & $(0.018)$ & $(0.021)$ & $(0.021)$ \\
postCT & 0.114 & 0.181 & -0.134 & 0.026 & -0.027 \\
& $(0.010)$ & $(0.016)$ & $(0.013)$ & $(0.009)$ & $(0.010)$ \\
\hline Observations & 2448 & 2448 & 2448 & 2447 & 2448 \\
Log_Likelihood & $-668,806.376$ & $-850,750.980$ & $-738,266.302$ & $-625,506.802$ & $-639,833.655$ \\
Relative_IRR & 1.106 & 1.070 & 0.974 & 0.954 & 0.927 \\
Relative_IRR_se & 0.051 & 0.049 & 0.037 & 0.030 & 0.027 \\
IRR_pvalue & 0.038 & 0.155 & 0.485 & 0.120 & 0.006 \\
Chi2_Stat & 4.809 & 2.231 & 5.010 & 1.266 & 7.855 \\
p_value & 0.307 & 0.693 & 0.286 & 0.867 & 0.097 \\
\hline \hline
\end{tabular}

This table reports estimates for the effect of access to federal marriage benefits for same-sex couples on disassortativeness of same-sex couples. Disassortativeness is measured as having: one partner born abroad and the other domestically (Birthplace), different races (Race), a student partner and non-student partner (Student), an education gap of five or more years (Education), or an age gap of three or more years (Age). The relative incidence rate ratio (IRR) is the exponentiated coefficient of interest. The $\chi^{2}$ statistic is for a test of parallel pre-trends. Standard errors are clustered at the group-state level. Created using the 20082019 rounds of the American Community Survey. 


\section{Table 21: DDDD Estimates Where Groups are Based on Disassor- tativeness Measures}

\begin{tabular}{lccccc}
\hline \hline & Birthplace & Race & Student & Education & Age \\
\hline post & -0.072 & -0.082 & -0.052 & -0.068 & -0.054 \\
postSSCT & $(0.006)$ & $(0.006)$ & $(0.006)$ & $(0.007)$ & $(0.006)$ \\
& -0.031 & 0.030 & -0.039 & -0.057 & -0.091 \\
postSSC & $(0.047)$ & $(0.047)$ & $(0.038)$ & $(0.031)$ & $(0.029)$ \\
& 0.366 & 0.340 & 0.377 & 0.379 & 0.414 \\
postCT & $(0.018)$ & $(0.017)$ & $(0.018)$ & $(0.021)$ & $(0.021)$ \\
& 0.154 & 0.196 & -0.132 & 0.025 & -0.029 \\
postMC & $(0.012)$ & $(0.017)$ & $(0.013)$ & $(0.009)$ & $(0.009)$ \\
& 0.117 & 0.092 & 0.080 & 0.082 & 0.081 \\
postSSMC & $(0.029)$ & $(0.015)$ & $(0.016)$ & $(0.016)$ & $(0.015)$ \\
& 0.260 & 0.225 & 0.258 & 0.255 & 0.160 \\
postDCCT & $(0.077)$ & $(0.062)$ & $(0.057)$ & $(0.059)$ & $(0.096)$ \\
postDDDD & -0.219 & -0.186 & -0.035 & -0.032 & -0.005 \\
& $(0.033)$ & $(0.028)$ & $(0.026)$ & $(0.022)$ & $(0.022)$ \\
Observations & 0.087 & 0.169 & 0.087 & 0.056 & 0.216 \\
Log_Likelihood & -1045630.152 & -1197032.705 & -1076873.142 & $-967,361.857$ & $-979,492.780$ \\
Relative_IRR & 0.970 & 1.031 & 0.962 & 0.945 & 0.913 \\
Relative_IRR_se & 0.046 & 0.048 & 0.037 & 0.029 & 0.026 \\
IRR_pvalue & 0.507 & 0.526 & 0.302 & 0.057 & 0.001 \\
Chi2_Stat & 6.313 & 1.867 & 5.786 & 1.512 & 7.376 \\
p_value & 0.177 & 0.760 & 0.216 & 0.825 & 0.117 \\
\hline \hline
\end{tabular}

This table reports estimates for the effect of access to federal marriage benefits for same-sex couples on disassortativeness of mixed-citizenship same-sex couples. Disassortativeness is measured as having: one partner born abroad and the other domestically (Birthplace), different races (Race), a student partner and non-student partner (Student), an education gap of five or more years (Education), or an age gap of three or more years (Age). The relative incidence rate ratio (IRR) is the exponentiated coefficient of interest. The $\chi^{2}$ statistic is for a test of parallel pre-trends. Standard errors are clustered at the group-state level. Created using the 2008-2019 rounds of the American Community Survey. 


\section{A.3.15 Main Result with pre-2013 Arrivals}

\section{Table 22: DDD Estimates for the Main Specification where all Non-Citizens Arrived pre-2013}

\begin{tabular}{lcc}
\hline \hline & Coupled Individuals & Married Individuals \\
\hline post & -0.078 & -0.769 \\
& $(0.005)$ & $(0.008)$ \\
post $\times \mathrm{M} \times \mathrm{SS}$ & 0.128 & 0.671 \\
& $(0.062)$ & $(0.193)$ \\
post $\times \mathrm{SS}$ & 0.374 & 1.416 \\
& $(0.018)$ & $(0.156)$ \\
post $\times \mathrm{M}$ & -0.048 & -0.275 \\
& $(0.016)$ & $(0.018)$ \\
\hline Observations & 2436 & 2367 \\
Log_Likelihood & $-842,932.311$ & $-1.389 \mathrm{e}+07$ \\
Relative_IRR & 1.137 & 1.955 \\
Relative_IRR_se & 0.070 & 0.378 \\
IRR_pvalue & 0.051 & 0.011 \\
Pre_Trend & 3.174 & 1.412 \\
p_value & 0.529 & 0.842 \\
\hline \hline
\end{tabular}

This table reports the $\overline{\overline{\text { Poisson Conditional Fixed Effects estimates for Equation }}}$ (1). SS refers to samesex coupled individuals and $\mathrm{M}$ refers to mixed-citizenship coupled individuals. The coefficient of interest is post $\times \mathrm{SS} \times \mathrm{M}$ and the Relative Incidence Rate Ratio (IRR) is the exponentiated coefficient of interest. The $\chi^{2}$ pre-trend test reports the test statistic for the test of parallel pre-trends, described by Equation (3). Standard errors in parentheses, clustered at the group-state level. Created using the the American Community Survey. Column 1, with coupled individuals, uses the 2008-2019 rounds. Column 2, with married individuals only, uses the 2012-2019 rounds. 


\section{A.3.16 Sex Heterogeneity}

\section{Table 23: Heterogeneity by Sex - DDD Estimates Restricted by Sex}

\begin{tabular}{lcccc}
\hline \hline & \multicolumn{2}{c}{ Women } & \multicolumn{2}{c}{ Men } \\
& Coupled & Married & Coupled & Married \\
\hline post & -0.065 & -0.856 & -0.065 & -0.856 \\
& $(0.007)$ & $(0.007)$ & $(0.007)$ & $(0.007)$ \\
postSSCT & 0.143 & 0.291 & 0.345 & 0.677 \\
& $(0.083)$ & $(0.243)$ & $(0.062)$ & $(0.225)$ \\
postSSC & 0.408 & 1.413 & 0.379 & 1.204 \\
& $(0.028)$ & $(0.220)$ & $(0.018)$ & $(0.196)$ \\
postCT & 0.080 & 0.159 & 0.080 & 0.159 \\
& $(0.017)$ & $(0.018)$ & $(0.017)$ & $(0.018)$ \\
\hline Observations & 1362 & 1246 & 1364 & 1260 \\
Log_Likelihood & $-319,134.228$ & -9681829.643 & $-321,213.562$ & -9630718.549 \\
Relative_IRR & 1.154 & 1.338 & 1.411 & 1.968 \\
Relative_IRR_se & 0.095 & 0.325 & 0.088 & 0.442 \\
IRR_pvalue & 0.106 & 0.298 & 0.000 & 0.028 \\
Pre_Trend & 2.443 & 3.365 & 2.686 & 1.294 \\
p_value & 0.295 & 0.186 & 0.261 & 0.524 \\
\hline \hline
\end{tabular}

This table reports the Poisson Conditional Fixed Effects estimates for Equation (1). SS refers to same-sex coupled individuals and $\mathrm{M}$ refers to mixed-citizenship coupled individuals. The coefficient of interest is post $\times \mathrm{SS} \times \mathrm{M}$ and the Relative Incidence Rate Ratio (IRR) is the exponentiated coefficient of interest. The $\chi^{2}$ pre-trend test reports the test statistic for the test of parallel pre-trends, described by Equation (3). Standard errors in parentheses, clustered at the group-state level. Created using the American Community Survey. Columns 1 and 3, with coupled individuals, uses the 2008-2019 rounds. Columns 2 and 4, with married individuals only, uses the 2012-2019 rounds. 


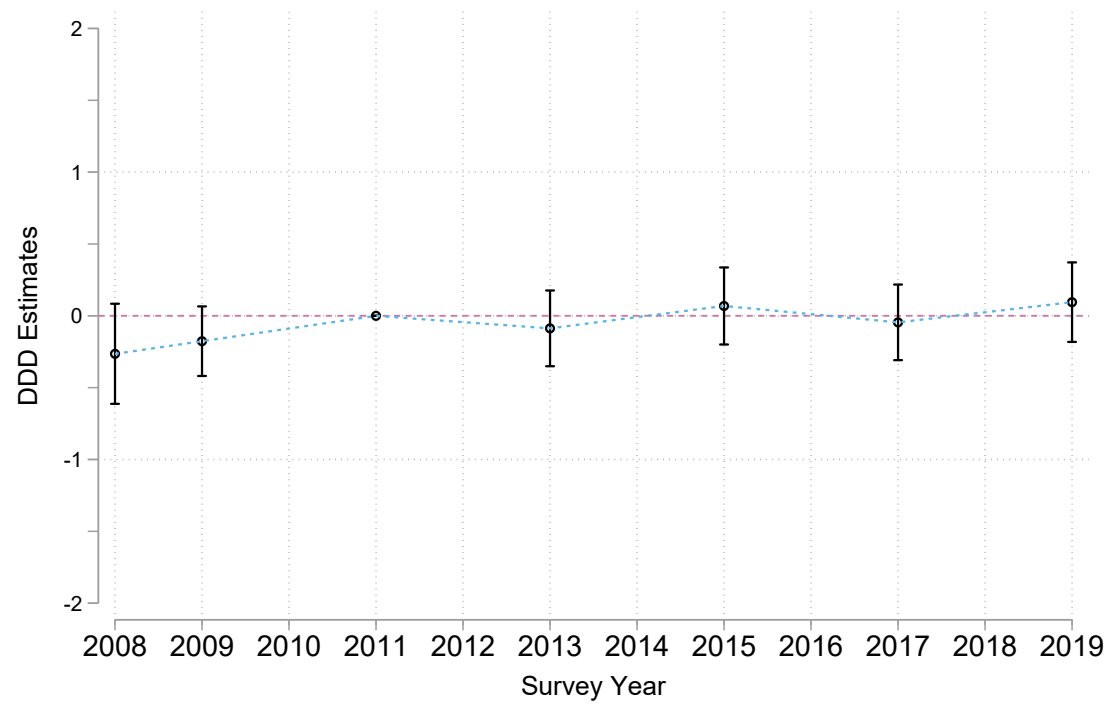

(a) Coupled Women by Survey Year

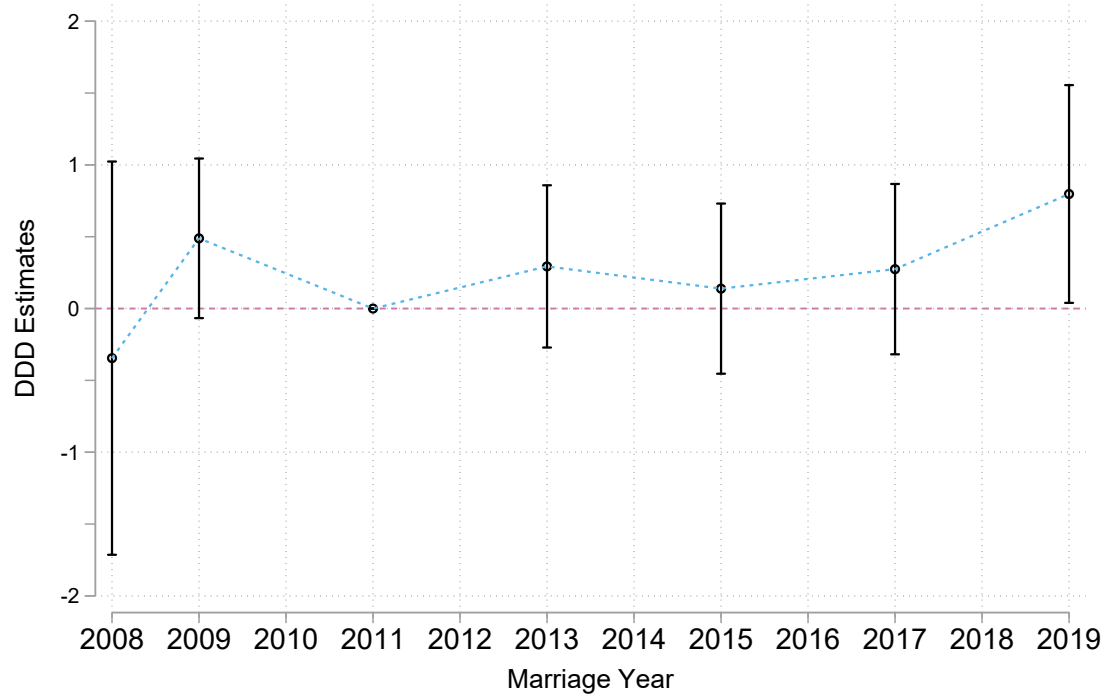

(b) Married Women by Marriage Year

\section{Figure 6: Dynamic DDD Estimates for Women}

This figure plots the Poisson Conditional Fixed Effects estimates for Equation (2), where time is either Survey Year or Marriage Year. The sample is restricted to women only. Standard errors are clustered at the group-state level. Data are from the American Community Survey. The first subfigure uses the 2008-2019 rounds; the second subfigure uses the 2012-2019 rounds. 


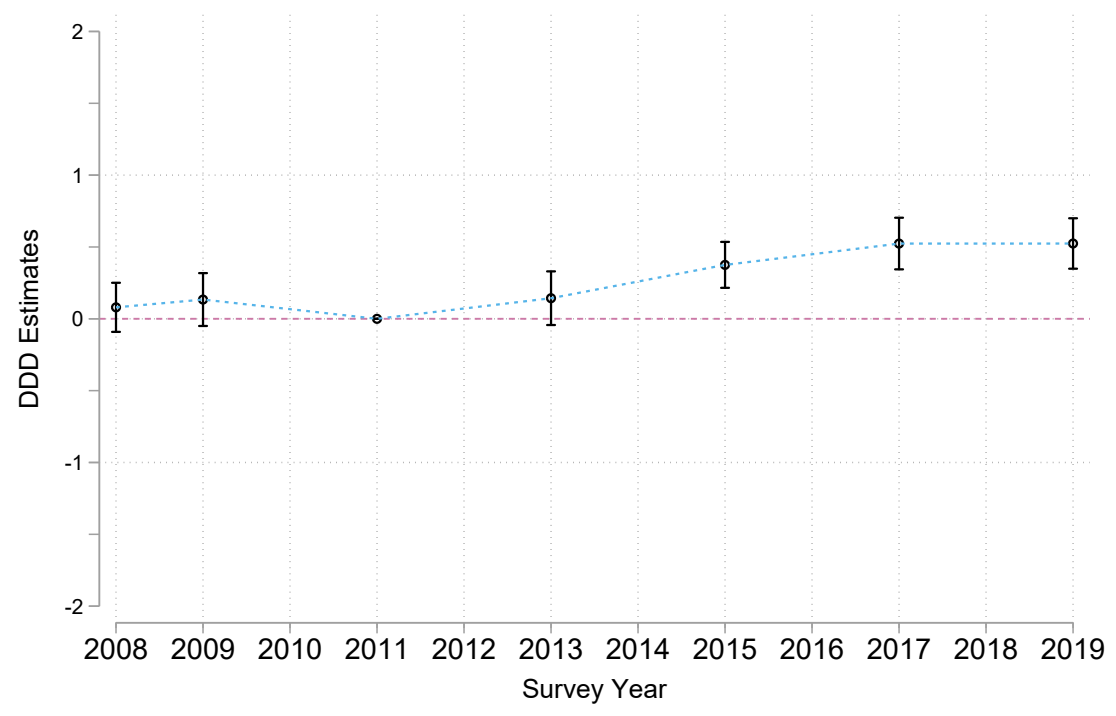

(a) Coupled Men by Survey Year

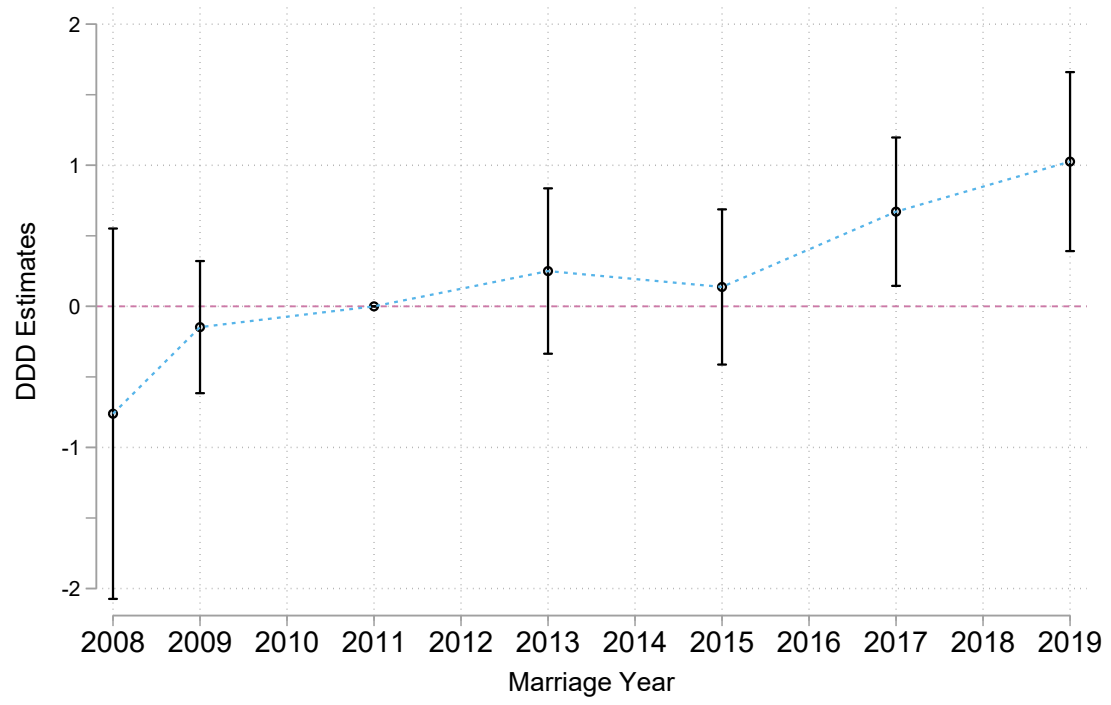

(b) Married Men by Marriage Year

\section{Figure 7: Dynamic DDD Estimates for Men}

This figure plots the Poisson Conditional Fixed Effects estimates for Equation (2), where time is either Survey Year or Marriage Year. The sample is restricted to men only. Standard errors are clustered at the group-state level. Data are from the American Community Survey. The first subfigure uses the 2008-2019 rounds; the second subfigure uses the 2012-2019 rounds. 


\section{A.3.17 Naturalisation}

It is difficult to estimate the downstream effect of spousal visa access onto naturalizations because as same-sex marriages increase then, mechanically, the number of naturalised persons married to a same-sex partner increases. I attempt to shed light onto whether or not spousal visa access leads to naturalisation by dividing couple according to whether or not a naturalisation could be due to a spousal visa. That is, individuals possibly naturalised through marriage are naturalised after three years of marriage to a citizen and individuals not naturalised through marriage are either unmarried, married to a non-citizen, or married to a citizen for less than three years. Figure 8 plots the number of naturalizations by couple type. Four years after the jump in mixed-citizenship same-sex marriages, there is an increase in naturalizations possibly through same-sex marriage, while other naturalizations are relatively constant. This could be because same-sex couples with spousal visas gain citizenship as well, or because there are many same-sex married couples by that time.

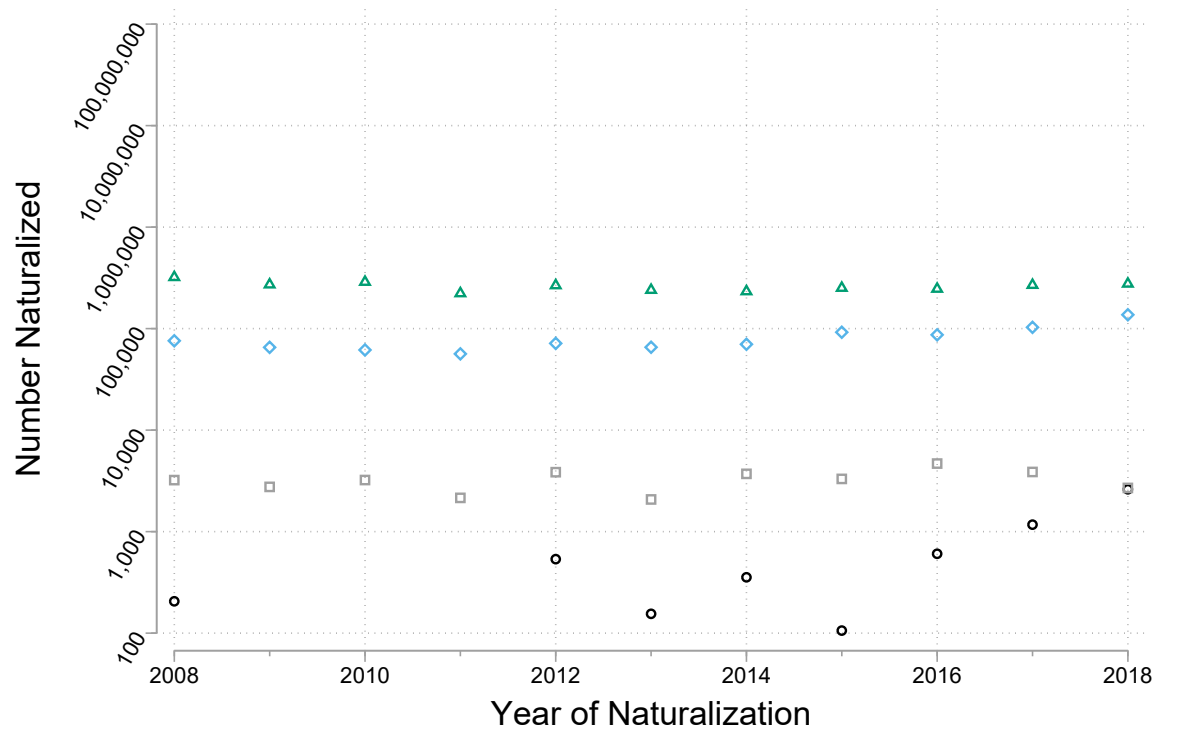

\section{Figure 8: Number of Naturalised Individuals by Naturalisation Year}

Each point represents the number of individuals in a given couple type by naturalisation year, representative of the United States population in 2019. The vertical axis depicts the number of naturalised individuals on a logarithmic scale. The horizontal axis depicts the year in which a partner is naturalised. The four couple types are determined by the intersection of same- or different-sex and possibly naturalised through marriage or not naturalised through marriage. Possible naturalisation through marriage means a naturalised individual married a citizen three or more years before naturalisation. Not naturalised through marriage means a naturalised individual is unmarried or married to a citizen for less than three years. Created using the 2019 round of the American Community Survey. 


\section{Table 24: DDD Estimates for Naturalised Coupled Individuals}

\begin{tabular}{lcc}
\hline \hline & \multicolumn{2}{c}{ Naturalized Coupled Individuals } \\
& by Survey Year & by Naturalization Year \\
\hline post & 0.068 & -1.210 \\
post $\times$ PNTM $\times$ SS & $(0.023)$ & $(0.020)$ \\
& 0.165 & 1.446 \\
post $\times$ SS & $(0.118)$ & $(0.231)$ \\
& 0.285 & 0.271 \\
post $\times$ PNTM & $(0.046)$ & $(0.172)$ \\
& 0.046 & 0.247 \\
Observations & $(0.028)$ & $(0.027)$ \\
Log_Likelihood & 1454 & 1221 \\
Relative_IRR & $-185,471.142$ & $-721,514.579$ \\
Relative_IRR_se & 1.180 & 4.244 \\
IRR_pvalue & 0.139 & 0.980 \\
Pre_Trend & 0.198 & 0.001 \\
p_value & 27.941 & 6.428 \\
\hline \hline
\end{tabular}

This table reports estimates for the relationship between access to federal marriage benefits for same-sex couples and naturalizations possibly resulting from same-sex marriage. Possible naturalisation through marriage (PNTM) means a naturalised individual married a citizen three or more years before naturalisation. Not naturalised through marriage means a naturalised individual is unmarried or married to a citizen for less than three years. The relative incidence rate ratio (IRR) is the exponentiated coefficient of interest. The $\chi^{2}$ statistic is for a test of parallel pre-trends. Standard errors are clustered at the group-state level. Created using the 2012-2019 rounds of the American Community Survey. 


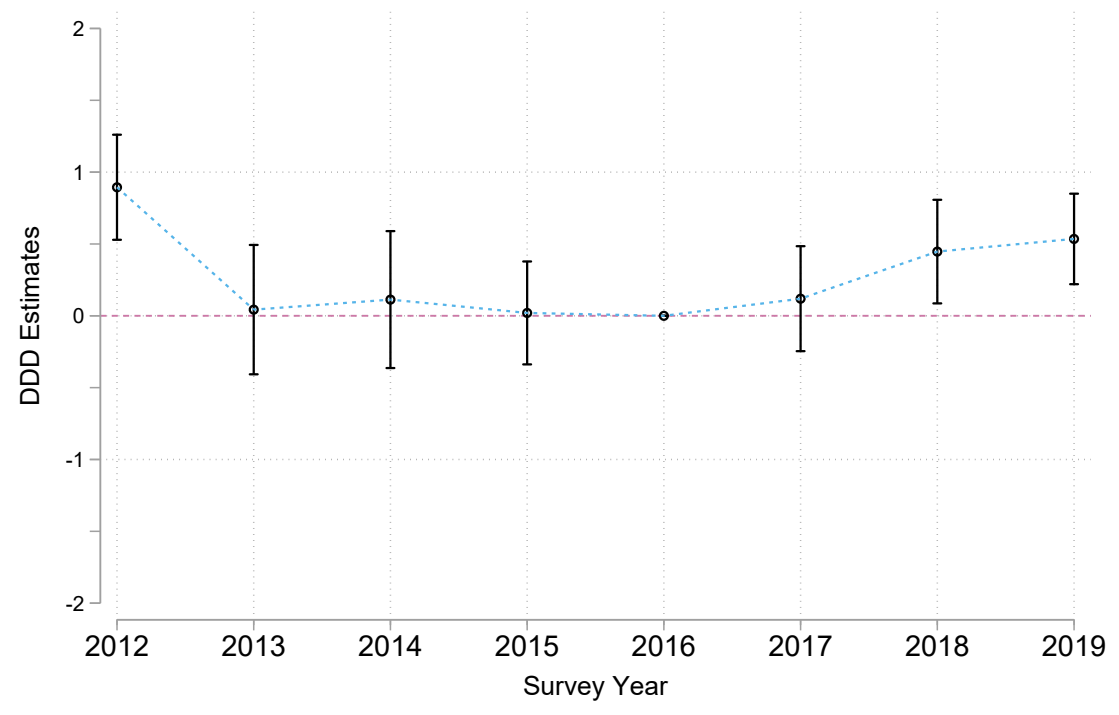

(a) Naturalised Individuals by Survey Year

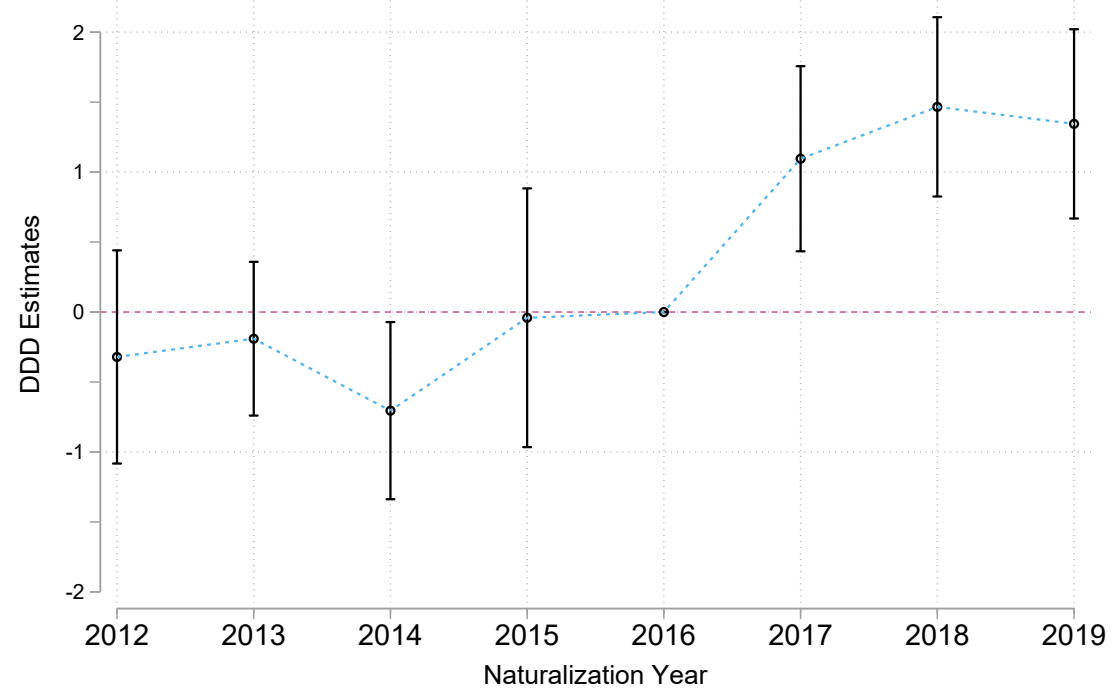

(b) Naturalised Individuals by Naturalisation Year

\section{Figure 9: Dynamic DDD Estimates for Naturalised Individuals}

This figure plots the Poisson Conditional Fixed Effects estimates for Equation [2], where time is either Survey Year or Naturalisation Year. The sample is restricted to naturalised individuals only. Standard errors are clustered at the group-state level. Data are from 2012-2018 rounds of the American Community Survey. 


\section{A.3.18 Main Result without Non-Citizen Same-Citizenship Couples}

\section{Table 25: DDD Estimates for the Main Specification where Same- Citizenship Couples are both Citizens}

\begin{tabular}{lcc}
\hline \hline & Coupled Individuals & Married Individuals \\
\hline post & -0.066 & -0.742 \\
& $(0.006)$ & $(0.006)$ \\
post $\times \mathrm{M} \times \mathrm{SS}$ & 0.301 & 0.575 \\
& $(0.053)$ & $(0.185)$ \\
post $\times \mathrm{SS}$ & 0.370 & 1.401 \\
& $(0.018)$ & $(0.157)$ \\
post $\times \mathrm{M}$ & 0.078 & 0.141 \\
& $(0.015)$ & $(0.016)$ \\
\hline Observations & 2448 & 2405 \\
Log_Likelihood & $-651,824.701$ & $-1.378 \mathrm{e}+07$ \\
Relative_IRR & 1.351 & 1.776 \\
Relative_IRR_se & 0.072 & 0.329 \\
IRR_pvalue & 0.000 & 0.018 \\
Pre_Trend & 2.830 & 1.293 \\
p_value & 0.587 & 0.862 \\
\hline \hline
\end{tabular}

This table reports the $\overline{\overline{\text { Poisson Conditional Fixed Effects estimates for Equation }}}$ (1). SS refers to samesex coupled individuals and $\mathrm{M}$ refers to mixed-citizenship coupled individuals. The coefficient of interest is post $\times \mathrm{SS} \times \mathrm{M}$ and the Relative Incidence Rate Ratio (IRR) is the exponentiated coefficient of interest. The $\chi^{2}$ pre-trend test reports the test statistic for the test of parallel pre-trends, described by Equation (3). Standard errors in parentheses, clustered at the group-state level. Created using the the American Community Survey. Column 1, with coupled individuals, uses the 2008-2019 rounds. Column 2, with married individuals only, uses the 2012-2019 rounds. 